\title{
The price effects of cross\#market mergers: theory and evidence from the hospital industry
}

\section{Citation}

Dafny, Leemore S., Katherine Ho, and Robin S. Lee. "The Price Effects of Cross-Market Mergers: Theory and Evidence from the Hospital Industry." RAND Journal of Economics 50, no. 2 (Summer 2019): $286-325$.

\section{Published Version}

https://doi.org/10.1111/1756-2171.12270

\section{Permanent link}

http://nrs.harvard.edu/urn-3:HUL.InstRepos:41844846

\section{Terms of Use}

This article was downloaded from Harvard University's DASH repository, and is made available under the terms and conditions applicable to Open Access Policy Articles, as set forth at http:// nrs.harvard.edu/urn-3:HUL.InstRepos:dash.current.terms-of-use\#OAP

\section{Share Your Story}

The Harvard community has made this article openly available.

Please share how this access benefits you. Submit a story.

\section{Accessibility}




\title{
The Price Effects of Cross-Market Mergers: Theory and Evidence from the Hospital Industry*
}

\author{
Leemore Dafny ${ }^{\dagger} \quad$ Kate Ho $\mathrm{Ho}^{\ddagger} \quad$ Robin S. Lee ${ }^{\S}$
}

May 31, 2018

\begin{abstract}
So-called "horizontal mergers" of firms whose products are direct substitutes at the point of sale have garnered significant attention from researchers and regulators alike. We consider the effect of mergers between firms whose products are not viewed as direct substitutes for the same good or service, but are bundled by a common intermediary. Focusing on the case of hospital mergers across distinct geographic markets ("cross-market" mergers), we show that such combinations can reduce competition among the merging firms for inclusion in insurers' networks, leading to higher prices (or lower-quality care). The result derives from the presence of "common customers" (i.e. purchasers of insurance plans) who value hospitals belonging to both merging parties, as well as (one or more) "common insurers" with which price and network status is negotiated. We test our theoretical predictions using two samples of cross-market hospital mergers, focusing exclusively on hospitals that are bystanders rather than the likely drivers of the transactions in order to address concerns about the endogeneity of merger activity. We find that hospitals gaining system members in-state (but not in the same geographic market) experience price increases of 7-10 percent relative to control hospitals, while hospitals gaining system members out-of-state exhibit no statistically significant changes in price. The former group are likelier to share common customers and insurers. The results suggest that crossmarket, within-state hospital mergers increase hospital systems' leverage when bargaining with insurers.
\end{abstract}

\footnotetext{
${ }^{*}$ We thank the editor, three anonymous referees, David Balan, Cory Capps, David Dranove, Gautam Gowrisankaran, Aviv Nevo, Bob Town, Nathan Wilson, and numerous conference and seminar participants for useful comments and discussion; and Matthew Schmitt and Victoria Marone for exceptional research assistance. All errors are our own.

${ }^{\dagger}$ Harvard Business School \& NBER, ldafny@hbs.edu.

${ }^{\ddagger}$ Columbia University, NBER \& CEPR, kh2214@columbia.edu.

${ }^{\S}$ Harvard University \& NBER, robinlee@fas.harvard.edu.
} 


\section{Introduction}

Merger analysis is a staple of antitrust enforcement. When a merger eliminates current or potential "head to head" competition for a relevant product or service, enforcers may sue to block or unwind the transaction. According to the most recent release of the "Horizontal Merger Guidelines," which articulate the principles followed by the federal antitrust enforcement agencies, merger analysis is a "fact-specific process," one in which the particulars of the relevant market(s) and merging parties are integral to enforcement decisions. One such particular is the presence (or absence) of intermediaries in the chain of production or distribution. In this study, we evaluate mergers of upstream suppliers to intermediaries that bundle products or services for sale to customers who in turn may aggregate the preferences of multiple individuals. We argue that the presence of intermediaries selling to such customers can affect both the likelihood and margin of harm from a merger of suppliers, even if the products being supplied are not direct "head to head" rivals at the point of sale. Examples of such settings include: cable TV, where different content producers offer channels that are not direct substitutes but negotiate prices with distributors that market a bundle of channels to multi-person households; and retail product markets where products may be targeted to different consumers but are stocked by retailers offering one-stop shopping.

Health insurance is another relevant example. Private (commercial) insurers bargain with providers (e.g., physicians or hospitals) over reimbursement rates (prices); the insurers then bundle these services, adding in administrative and oversight features - as well as risk-bearing in the case of "full insurance" products - and sell insurance plans to employers and households. Hospitals are critical upstream suppliers to health plans, accounting for nearly one-third of health care spending in the U.S. today 1 In recent years, the Federal Trade Commission (FTC) has successfully challenged several proposed mergers of hospitals that are direct substitutes at the point of care (i.e. in the same geographic and product market), informed by an economic literature showing that these "within-market" mergers tend to result in price increases for privately-insured patients without significant quality improvements ${ }^{2}$

In contrast there has been very little regulatory activity regarding hospital mergers across distinct markets. This gap is notable in light of the significant pace of such "cross-market" mergers in recent years $3^{3}$ More than half of the 528 general acute care hospital mergers between 2000 and 2012 involved hospitals or systems without facilities in the same CBSA 4 and a recent study by

\footnotetext{
${ }^{1}$ CMS National Health Expenditure Accounts, available at https://www.cms.gov/research-statistics-data-andsystems/statistics-trends-and-reports/nationalhealthexpenddata/nhe-fact-sheet.html

${ }^{2}$ See Dranove and White (1994); Town and Vistnes (2001); Capps, Dranove and Satterthwaite (2003); Gaynor and Vogt (2003); Dafny (2009); Haas-Wilson and Garmon (2011); Farrell et al. (2011); Gaynor and Town (2012); Gaynor, Ho and Town (2015) among others.

${ }^{3}$ Examples include the $\$ 3.9$ billion acquisition of Health Management (71 hospitals) by Community Health Systems (135 hospitals) in 2014, and the 2013 merger of Dallas-based Baylor Health Care System and Temple-based Scott \& White Health; post-merger the combined entity comprised 43 hospitals and more than 6,000 affiliated physicians.

${ }^{4}$ Data from Irving Levin on 528 general acute care hospital mergers between 2000-2012 indicate that 256 (48.5\%) involved hospitals located within the same CBSA; 193 (36.6\%) were in the same state but not the same CBSA; while $79(15 \%)$ were out of state. A CBSA is defined as a metropolitan statistical area in larger cities, and a "micropolitan" area in smaller towns. For further details, see www.census.gov/programs-surveys/metro-micro/about.html.
} 
Lewis and Pflum (2016) shows substantial increases in prices for independent hospitals acquired by out-of-market systems (located $45+$ minutes away), as well as price increases by nearby rivals. As we describe below, current methods of assessing the anticompetitive threat from hospital mergers assume there can be no increase in bargaining leverage unless the merging parties are vying to provide the same set of services to the same set of patients. These methods implicitly assume that insurance markets do not impact upstream market power; more formally, the models typically assume insurers face demand that is separable across product and service markets (as in Capps, Dranove and Satterthwaite (2003)).

We argue that an extension to the current methodology is warranted in light of the role and realities of intermediary markets. Insurers negotiate with and pay hospitals for their services, and demand for insurance may not, in fact, be separable across service markets. We show that the presence of "common customers" (e.g., employers or households) who purchase insurance products and value the services of hospitals in both merging parties can give rise to greater post-merger bargaining leverage for the merging hospitals even when those hospitals operate in distinct patient markets. These common customers are likely to be large employers that demand insurance products covering hospital services in multiple distinct geographic markets, i.e. areas where their employees live and work. Since insurers serve employers across multiple geographic regions, a merged crossmarket hospital system that covers those regions can demand higher reimbursement rates from insurers 5

Consider for illustrative purposes a simple setting where a state-wide employer chooses insurance products to offer to employees who are evenly distributed across the state. Assume there are ten local markets, each of which contains three evenly-sized, competing hospitals. Insurers engage in pair-wise bargaining with hospitals over prices. Under current antitrust practice, authorities would be likely to object to mergers of hospitals within a local market on the grounds that they would "substantially lessen competition or tend to create a monopoly," per Section 7 of the Clayton Act ${ }^{6}$ They would be unlikely, however, to object to cross-market mergers - even repeated mergers that created three large hospital systems, each owning a hospital in every market. However, the cross-market presence of the large employer implies a potentially large effect of these mergers on negotiated hospital prices. While the employer would be unlikely to drop an insurance plan that removed just one of the thirty hospitals from its network (since this would affect few of its employees), it would be much more likely to drop a plan that removed a large hospital system representing a third of all hospitals. Thus, competition among insurers for inclusion in employers' plan menus provides the large hospital system with greater bargaining leverage than individual hospitals to negotiate higher prices, even if no two hospitals in the system operate in overlapping service markets.

The first part of this paper uses a theoretical model of bargaining between upstream suppliers

\footnotetext{
${ }^{5}$ Common customers for insurance products can also be households that demand services of hospitals in the same geographic area but different product markets, e.g. pediatric and cardiac specialty hospitals.

${ }^{6}$ Throughout this manuscript, we refer to "price effects," but our theoretical and conceptual observations apply equally to other potential merger effects, such as effects on quality or innovation.
} 
and downstream intermediaries to formalize the intuition outlined above. Building on the model in Ho and Lee (2017), we show that a sufficient condition for a market power effect of an upstream merger between hospitals is that the insurer's objective function, typically represented by its profits, is submodular in the set of upstream hospitals - i.e., the value of a hospital to an insurer is decreasing in the size of the insurer's hospital network. This condition can be satisfied under standard formulations for consumer demand and insurer profits if the hospitals are valued by a common customer (e.g. employer or household) even if they operate in different service markets. Our model formalizes some of the arguments in Vistnes and Sarafidis (2013), which includes numerical examples illustrating how price effects may arise when employers recruit employees from different geographic areas. We also provide conditions under which a merger between hospitals negotiating with a common insurer, even absent common customers, is sufficient to generate a price effect 7

The second part of the paper explores the predictions of our model using panel data on hospital prices and system acquisitions, supplemented with data on local insurance market shares. We examine two distinct samples of acute-care hospital mergers over the period 1996-2012, and compare the price trajectories of three groups of hospitals: (i) hospitals acquiring a new system member in the same state but not the same narrow geographic market ("adjacent treatment hospitals"); (ii) hospitals acquiring a new system member out of state ("non-adjacent treatment hospitals"); and (iii) hospitals that are not members of "target" (i.e., acquired) or acquiring systems. To minimize concerns about the exogeneity of which hospitals are parties to transactions, we focus on hospitals that are likely to be "bystanders" rather than the drivers of transactions. Our first sample of transactions comprises mergers investigated by the FTC due to potential horizontal overlap among the merging parties. We argue that hospitals outside of the areas of concern likely fall into the bystander category. Our second sample comprises the set of all system mergers over the period 2002-2012. Here we limit the treatment group in two ways: first, to hospitals that are not the "crown jewels" of each deal and are neither party to nor located near another merger over a 5 year period spanning the transaction of interest. Second, we remove target hospitals altogether and consider the effect of the merger on acquirers' prices.

We find that prices for adjacent treatment hospitals increase by 7-10 percent relative to control hospitals. The estimates for non-adjacent treatment hospitals are small, generally negative, and statistically insignificant. Our results also show that acquirers are raising their own prices, suggesting that significant quality improvements (such as might arise for targets following a takeover) are unlikely to be the source of price increases. Additional analyses reveal that price effects are largest when the merging parties have hospitals in closer geographic proximity (i.e., 30-90 minutes' drive from one another; hospitals less than 30 minutes apart are dropped as they are likely to be considered "same market" combinations). We also find suggestive evidence of larger price effects when the acquiring and target systems share common insurers. We argue that these findings support the hypothesis that common customers give rise to positive price effects and suggest that alternative

\footnotetext{
${ }^{7}$ Depending on the precise mechanism, these effects may not arise from a diminution of competition among the merging entitites.
} 
mechanisms are less empirically plausible.

A small number of previous papers consider the impact of cross-market mergers in the health care setting. Peters (2014) is a theoretical paper, complementary to ours, which uses a fully specified bargaining model to identify conditions under which the merger of suppliers can generate an increase in supplier prices even when the suppliers' products are not substitutes. As in our model, a necessary condition for a cross-market effect is the existence of common customers who value both merging parties. However, Peters emphasizes a mechanism that does not require the insurer's objective function to be submodular in the provider network: changes in hospitals' disagreement points upon merging (see also Ho and Lee (2017)) 8

The empirical paper most closely related to ours is Lewis and Pflum $(2016)$, who use a differencein-differences analysis to analyze the impact of cross-market hospital mergers on prices of targets. They find independent hospitals acquired by out of market systems raise price by 17-18 percent, and the effects are larger when the acquiring system is larger or when the acquired hospital is smaller (by number of beds). They argue that greater post-merger bargaining weight (usually captured by the bargaining parameter in a Nash bargaining game) is the most credible explanation for the results. An earlier paper, Lewis and Pflum (2015) estimates the division of surplus in insurer-hospital contract negotiations, and concludes that the bargaining weight of a hospital is increasing in system size. Relatedly, Grennan (2013) specifies and estimates a bargaining model that demonstrates the importance of heterogeneous bargaining weights in the context of price negotiations between hospitals and medical device suppliers. Thus, these papers suggest a crossmarket acquisition could result in a price increase due to a change in bargaining weight, rather than in bargaining position. As we discuss in Section 5, our findings are complementary to these papers, as our "treatment" hospitals consist primarily of hospitals belonging to larger systems that acquire a single target. These hospitals are different from the independent targets studied by Lewis and Pflum (2015), and less likely to experience a significant change in bargaining weight or skill.

Last, our study complements a recent study by Gowrisankaran, Nevo and Town (2015), who estimate a model of hospital-insurer bargaining and use it to predict the price effects of withinmarket hospital mergers. Their baseline model does not allow for our common customer effect since it assumes that insurers do not compete for enrollees. The authors argue that in settings where patients are exposed to negotiated prices via coinsurance rates, cross-market mergers may generate price effects if insurers can utilize coinsurance rates to steer patients away from higherpriced hospitals; they also note that cross-market price effects can arise when insurers compete with one another.

Our contribution to this literature is two-fold. We provide a formal theoretical model that is broadly relevant for markets with intermediaries, that illustrates how cross-market mergers between

\footnotetext{
${ }^{8}$ Under this circumstance, a merger can improve the hospitals' bargaining position if they face smaller losses from disagreement when they negotiate jointly because of the possibility of recapturing lost volume through enrollment of disenchanted insurance customers in rival insurers' plans (a "recapture effect"). While our empirical tests do not explicitly examine the recapture effect, we note that - even if present - this mechanism is consistent with a diminution of competition among merging parties.
} 
upstream suppliers can generate price effects, and that provides examples of situations where this is likely to occur. Importantly, the common customer effect results from a change in parties' outside options (or threat points) when bargaining. A positive price effect can arise if the intermediary suffers a larger profit reduction if both suppliers leave its network than the combined sum of profit reductions that would arise from removing each supplier separately. It is not predicated on an assumption that suppliers' bargaining skill (or Nash bargaining parameter) is affected by a merger (as in Lewis and Pflum, 2015, 2016), or on the existence and magnitude of coinsurance (as in Gowrisankaran, Nevo and Town, 2015), and is the result of a lessening of competition among the merging parties for inclusion in insurers' provider networks. We also provide robust empirical evidence of price effects of cross-market mergers, expanding the sample considered in Lewis and Pflum (2016), employing an empirical strategy to help address concerns regarding endogenous choice of merger targets, and isolating effects on acquirers rather than targets. We find evidence consistent with common customers driving the estimated price effect in our sample, and present empirical tests ruling out several alternative mechanisms.

\section{Theoretical Model}

In this section, we develop a stylized model of hospital-insurer bargaining over inclusion of the hospital in the insurer's network, and the price(s) to be paid by the insurer for care received by enrollees. Although we focus on the health care context, the model is applicable more broadly if one conceives of hospitals as "upstream" suppliers of medical services to "downstream" insurers that, in turn, bundle those services (along with other components, such as utilization review and claims processing) into insurance products. Consequently, the effects that we highlight may also be present in other vertical markets in which upstream firms sell products through downstream intermediaries.

\subsection{Overview}

Our theoretical framework considers two hospitals bargaining with a common insurer over reimbursement rates. We assume that if the hospitals are independent, they bargain separately with the insurer over hospital services; if the hospitals merge, they bargain jointly with the downstream intermediary. The difference between the two settings is that when hospitals bargain separately, disagreement in one bargain results in only one hospital being removed from the insurer's network; when hospitals bargain jointly, both hospitals are removed.

We first note that a market power effect of any hospital merger-i.e., an outcome where the merged hospitals are able to negotiate higher reimbursement prices without an increase in quality or bargaining effectiveness - will arise if the sum of the marginal contributions of each hospital to the insurer's objective (e.g., profits) is less than the marginal contribution of both hospitals jointly to the insurer. In other words, the market power effect will arise if the insurer is harmed more by losing both hospitals jointly than the combined effect of losing each hospital separately. 
We show that if the two hospitals are located in separate geographic or diagnostic markets, and the insurer's objective is separable across markets - i.e., there are no interdependencies that arise between these markets - then this condition cannot hold. The standard analysis employed by the FTC in hospital merger cases (cf. Farrell et al., 2011) implicitly satisfies this separability condition, and thus does not admit the possibility for cross-market mergers to yield price effects due to an increase in market power.

However, this standard analysis can be extended to capture additional institutional details that characterize the U.S. commercial health care industry. In particular, insurers often sell plans to employers or individuals who value hospitals in multiple diagnostic and/or geographic markets. If two merging parties serve customers who value the services of both, the existence of these "common customers" creates linkages across the markets in which the parties operate. If the links are sufficiently strong (i.e., the insurer serves many common customers of the merging parties), a merger may be able to increase the bargaining leverage of the merging parties vis a vis the insurer that sells plans to the common customers.

We provide two examples of such common customers. The first example comprises households; a household chooses an insurance plan that best satisfies the different medical needs of all of its members, subject to budget constraints. This objective will generate a linkage across providers serving distinct diagnostic markets. The second example comprises multi-market employers; an employer typically chooses an insurance plan for its employees based on the insurer's network of hospitals across all the markets in which employees work and reside, thus creating a linkage across otherwise separate geographic markets.

Finally, we discuss limiting factors for this mechanism, and the empirical patterns that help to disentangle our explanation from other potential sources of cross-market merger effects.

\subsection{Basic Model}

Consider two upstream suppliers (hospitals), $h \in\left\{h_{1}, h_{2}\right\}$, bargaining with a monopolist downstream intermediary (insurer). For the sake of exposition, we present a stylized version of a bargaining model that highlights our key theoretical points; see Ho and Lee (2017) for a more generalized treatment of hospital-insurer bargaining 9

Let $\Phi(\mathcal{G})$ represent the insurer's objective for a given "network" $\mathcal{G}$ of hospitals, where $h \in \mathcal{G}$ indicates that hospital $h$ is in the insurer's network, and $\pi_{i}(\mathcal{G})$ be the hospital's profits (net of payments made from the insurer). To convey intuition, assume that each hospital engages in a bilateral Nash bargain with the insurer over a lump sum reimbursement, anticipating that all other hospitals in $\mathcal{G}$ also reach an agreement with the insurer; this implies that the negotiated

\footnotetext{
${ }^{9}$ The more general model incorporates competition among different insurers with different hospital networks, bargaining over linear per-admission reimbursement rates, and asymmetric Nash bargaining, and explicitly models consumer demand for hospitals and household demand for insurers.
} 
reimbursement paid to hospital $h$, denoted $p_{h}$, satisfies:

$$
p_{h}=\arg \max _{p} \underbrace{\left[\Phi(\mathcal{G})-p_{h}-\Phi(\mathcal{G} \backslash h)\right]}_{\text {Insurer's "gains-from-trade" }} \times \underbrace{\left[\pi_{h}(\mathcal{G})+p_{h}\right]}_{\text {Hospital's "gains-from-trade" }} \quad h \in\left\{h_{1}, h_{2}\right\}
$$

where $\Phi(\mathcal{G} \backslash h)$ represents the insurer's objective when hospital $h$ is removed from its network $\mathcal{G}{ }^{10}$ For simplicity, we assume that if hospital $h$ is removed from the insurer's network, the rest of the insurer's network does not change and the hospital earns 0 profits 11 The Nash bargaining solution applied in this fashion to multiple bilateral bargains has been referred to as the "Nash-in-Nash" solution, and has been employed in both non-health (Villas-Boas (2007), Crawford and Yurukoglu (2012)) and health (Grennan (2013), Gowrisankaran, Nevo and Town (2015), Ho and Lee (2017)) settings; see Collard-Wexler, Gowrisankaran and Lee (forthcoming) for further discussion.

The first-order condition of (1) for each hospital $h \in\left\{h_{1}, h_{2}\right\}$ is

$$
p_{h}^{*}=\left(\Phi(\mathcal{G})-\Phi(\mathcal{G} \backslash h)-\pi_{h}(\mathcal{G})\right) / 2,
$$

which implies that the negotiated payment splits the "gains-from-trade" created when a hospital is included in an insurer's network. Summing across this condition for both hospitals yields total (pre-merger) payments of:

$$
P^{\text {pre-merger }} \equiv \sum_{h \in\left\{h_{1}, h_{2}\right\}} p_{h}^{*}=\sum_{h \in\left\{h_{1}, h_{2}\right\}}\left(\Phi(\mathcal{G})-\Phi(\mathcal{G} \backslash h)-\pi_{h}(\mathcal{G})\right) / 2 .
$$

The Impact of a Merger on Total Prices. In this simple environment, we are interested in the price effect of a merger between hospitals $h_{1}$ and $h_{2}$. To highlight the market power effects of interest, assume that there are no cost efficiencies or quality adjustments due to a merger, and that the merged hospital system continues to Nash bargain with the insurer over reimbursements; this implies that the hospitals' profit functions $\left\{\pi_{h}\right\}_{h \in\left\{h_{1}, h_{2}\right\}}$ (which are net of negotiated prices and can contain costs and other sources of revenue) are unchanged by the mergers. The new negotiated prices for each hospital within the system $\mathcal{S} \equiv\left\{h_{1}, h_{2}\right\}$ will solve the reformulated Nash bargain:

$$
\mathbf{p}^{M}=\arg \max _{\left\{p_{h}^{M}\right\}_{h \in\left\{h_{1}, h_{2}\right\}}}\left[\Phi(\mathcal{G})-\left(\sum_{h \in\left\{h_{1}, h_{2}\right\}} p_{h}^{M}\right)-\Phi(\mathcal{G} \backslash \mathcal{S})\right] \times\left[\sum_{h \in\left\{h_{1}, h_{2}\right\}}\left(\pi_{h}(\mathcal{G})+p_{h}^{M}\right)\right],
$$

where we have assumed that, upon disagreement with any one merging hospital, the insurer loses access to both hospitals in the system. The change in the disagreement point alters the Nash bargaining solution, as the first-order condition of (4) for either hospital $h \in\left\{h_{1}, h_{2}\right\}$ can be

\footnotetext{
${ }^{10}$ Asymmetric bargaining weights are omitted from this equation for ease of exposition. Their omission does not affect subsequent analysis.

${ }^{11}$ If there are competing insurers (and hospitals contract with multiple insurers), the analysis can be extended to account for changes in hospitals' disagreement points upon merging (see Peters, 2014, Ho and Lee, 2017); however, the effects that we focus on here will still be present.
} 
expressed as:

$$
P^{\text {post-merger }} \equiv \sum_{h \in\left\{h_{1}, h_{2}\right\}} p_{h}^{M, *}=\left(\Phi(\mathcal{G})-\Phi(\mathcal{G} \backslash \mathcal{S})-\sum_{h \in\left\{h_{1}, h_{2}\right\}} \pi_{h}(\mathcal{G})\right) / 2
$$

A comparison of (3) with (5) implies that the total payment to the hospital system will be greater than the sum of pre-merger payments (ie., $P^{\text {post-merger }}>P^{\text {pre-merger }}$ ) if:

$$
\Phi(\mathcal{G})-\Phi(\mathcal{G} \backslash \mathcal{S})>\sum_{h \in\left\{h_{1}, h_{2}\right\}}(\Phi(\mathcal{G})-\Phi(\mathcal{G} \backslash h)) .
$$

That is, payments will increase if the reduction in an insurer's objective function from losing the system exceeds the sum of the reductions from losing each hospital separately.

A sufficient condition for (6) to hold, and for a merger to increase negotiated payments, is for the insurer's objective to be strictly submodular in its network of hospitals: i.e., the value of each hospital to the insurer is lower when the insurer's network is larger (e.g., when the other hospital is on the network than when the other hospital is removed), which is typically satisfied when hospitals are substitutable for one another ${ }^{12}$ We refer to such a merger as one that increases the hospitals' bargaining leverage.

In contrast, if the sum of the losses from excluding either hospital individually exceeds the loss from excluding both simultaneously so that the inequality in (6) is reversed, then a merger may potentially lead to a reduction in negotiated reimbursement rates under Nash bargaining. This can occur, for example, if the two merging hospitals are sufficiently strong complements so that an insurer can only obtain significant revenues, or remain solvent and avoid bankruptcy, if it contracts with both hospitals as opposed to only one (cf. Chipty and Snyder, 1999, Easterbrook et al., 2017).13

Ultimately, determining whether the condition in (6) holds is an empirical exercise. As discussed above, this will in turn depend on the set of other hospitals contained in the insurer's network $\mathcal{G}$, and on whether an insurer views the merging hospitals as substitutes or complements given this network.

\footnotetext{
${ }^{12}$ If $\Phi(\cdot)$ is strictly submodular, then $\Phi(\mathcal{G})-\Phi\left(\mathcal{G} \backslash h_{1}\right)<\Phi\left(\mathcal{G} \backslash h_{2}\right)-\Phi\left(\mathcal{G} \backslash\left\{h_{1}, h_{2}\right\}\right)$ (i.e., the value of $h_{1}$ to the insurer is lower when $h_{2}$ is in the insurer's network than when $h_{2}$ is not); combining this with similar condition for $h_{2}$ yields 6 .

${ }^{13}$ However, as discussed in Collard-Wexler, Gowrisankaran and Lee (forthcoming), the Nash-in-Nash bargaining solution may not be an appropriate surplus division rule in environments with strong complementarities among contracting parties. Consequently, if hospitals are strong complements from the perspective of an insurer prior to merging, condition (6) - derived from this bargaining solution-may not be appropriate for determining whether a price decrease will occur.
} 


\subsection{No Price Effects When Markets are Separable}

Assume now that $h_{1}$ and $h_{2}$ are located in different markets $m \in\{1,2\}$. If the insurer's profits (i.e., both costs and demand) are separable across these markets so that

$$
\Phi(\mathcal{G})-\Phi(\mathcal{G} \backslash \mathcal{S})=\sum_{m \in\{1,2\}}\left(\Phi_{m}(\mathcal{G})-\Phi_{m}\left(\mathcal{G} \backslash h_{m}\right)\right)
$$

(where $h_{m}$ indicates the hospital in market $m$ ), then $P^{\text {post-merger }}=P^{\text {pre-merger }}$ and there will be no change in bargaining leverage arising from a cross-market merger.

The condition in (7) is implicitly imposed by the standard approach used in the hospital merger literature (Capps, Dranove and Satterthwaite (2003), Farrell et al. (2011)) ${ }^{14}$ In particular, these models assume that an insurer's objective function when bargaining with hospitals is a linear function of individuals' "willingness-to-pay" (WTP) for the insurer's network. This WTP variable, constructed from a model of individual demand for hospitals, represents the individual's expected utility or option value from being able to access the insurer's network of hospitals in the event of a need for hospitalization. In Appendix A, we define WTP and detail its construction.

One important feature of $W T P$ is that it is typically submodular in the set of hospitals within the same diagnostic and geographic market. Assuming consumers view hospitals in the same market as substitutes, the sum of the reductions in WTP from losing one hospital but retaining access to the other is less than the change in WTP from losing both simultaneously (Capps, Dranove and Satterthwaite, 2003). Thus, if an insurer's objective were captured by the WTP it generated for potential enrollees, then a within-market merger of two hospitals (i.e., in the same diagnostic and geographic market) would be predicted to increase the hospitals' bargaining leverage and generate a higher post-merger price.

However, individuals' WTP (as typically formulated) is additively separable across different diagnostic categories (e.g., for a given individual, the WTP of an insurer's network for cancer can be separated from the WTP for obstetric services) and geographic markets (as individuals are assumed to derive utility only from hospitals within their own geographic market). Consequently, assuming that an insurer maximizes a linear function of WTP for all of its enrollees typically implies that a cross-diagnostic market or cross-geographic market provider merger will not be predicted to yield a negotiated price change.

\subsection{Common Customers and Non-Separable Markets}

The assumption that the insurer's objective $\Phi$ is linear in WTP is stylized, and was adopted for analytic convenience. It is probably more realistic to assume that insurers maximize profits, which are a function of both the WTP generated for enrollees and the nature of demand faced by the insurer. If there are common customers for the insurer who value both hospitals at the time of choosing an insurance plan, then a simple extension of the standard analysis can generate a change

\footnotetext{
${ }^{14}$ Absent coinsurance rates, the baseline model in Gowrisankaran, Nevo and Town $(2015)$ also implies this condition.
} 
in bargaining leverage from a cross-market hospital merger. We now present two examples of such common customers.

\subsubsection{Linking Diagnostic Markets Via a Common Customer: Households}

Consider first a household (or family) that chooses an insurance plan to satisfy the needs of all its members. This is the assumption made by Ho and Lee (2017), in which households $f$ choose an insurance plan $j$ in geographic market $m$ to maximize a utility function similar to:

$$
u_{f, j, m}=\delta_{j, m}+\sum_{k \in f} \alpha_{k} W T P_{k, j, m}\left(\mathcal{G}_{j}\right)+\varepsilon_{f, j, m}
$$

where $\delta_{j, m}$ are plan-market fixed effects, $W T P_{k, j, m}\left(\mathcal{G}_{j}\right)$ is the WTP generated by plan $j$ in market $m$ for individual $k$ in the household, and $\varepsilon_{f, j, m}$ is an i.i.d. demand shock. This utility specification generates demand for insurer $j$ that is typically non-linear in the WTP that it offers to different individuals. The intuition is simply that a household's insurance choice will depend on the needs of all of its members, so if the insurer maximizes an objective (such as profit) that is a function of its demand, then a merger of providers potentially serving different members can impact the merging parties' bargaining leverage vis a vis the insurer 15 In Appendix B, we provide another example of a demand setting where price effects can arise from cross-diagnostic market mergers.

\subsubsection{Linking Geographic Markets Via a Common Customer: Employers}

The second example of a common customer is an employer that chooses an insurance plan to offer to employees who live and/or work in multiple geographic markets. This particular common customer effect is discussed in Vistnes and Sarafidis (2013); we formalize it here.

In the large-group employer-sponsored health insurance market, employers are typically the direct customers for insurance plans in that they determine the menu of plans from which their employees choose and negotiate the financial terms of those plans (e.g., premiums and cost-sharing arrangements). We provide intuition for how competition among insurers to be included in an employer's choice set introduces cross-market linkages, and hence bargaining effects arising from cross-market hospital mergers. The following example is one in which there is a positive price effect from a cross-market merger. However, as noted above, the direction of a cross-market effect in any particular setting may not be possible to sign theoretically.

Consider the simple situation where an employer offers an insurance plan $j$ to its employees if its gains from offering the plan exceed some threshold $F$ The employer's objective, denoted $W(\mathcal{M})$, is a function of the welfare gains that its employees receive from having access to a particular choice

\footnotetext{
${ }^{15}$ If a household comprises multiple individuals, then diagnostic markets that are valued by different members of the household (e.g., pediatrics and obstetrics) will be linked together when the plan choice is made. Even if a household comprises only a single individual, the fact that the individual values the services of two providers in different diagnostic markets at the time of choosing an insurance plan induces a cross-diagnostic market linkage.

${ }^{16}$ Such a threshold can arise from a fixed cost of offering each additional plan or from competition from another insurance plan (in which case $F$ would be an endogenous equilibrium object).
} 
set of insurers $\mathcal{M}$. Thus, if $\Delta W(\mathcal{M}, j)$ is the additional welfare generated by an insurance plan $j$ for an employer's choice set, then the employer will choose not to offer the plan to its employees if $\Delta W(\mathcal{M}, j)<F{ }^{17}$ Note that this formulation is quite general: it does not require that an employer weights the welfare generated for all employees equally; it also allows the firm to require (through appropriate market-level thresholds in $W(\mathcal{M}, j)$ ) that employees in a particular market all receive a minimal level of insurance coverage or access.

In this setting, hospitals located in different geographic markets can, upon merging, increase their negotiated reimbursement rates from the insurer. For example, assume that if the insurer has at least $H_{1}$ or $H_{2}$ in its network, then $\Delta W(\mathcal{M}, j) \geq F$ and it will be offered by the employer. However, if it loses both, then $\Delta W(\mathcal{M}, j)<F$ and the insurer will be dropped by the firm and earn 0 . In this example the cutoff value $F$ implies a larger impact on the insurer's objective function upon losing the combined hospital system. Under reasonable conditions, the insurer's objective function will satisfy the properties of (6). That is, since $\Phi(\mathcal{G} \backslash \mathcal{S})=0$, equation (6) implies that there will be a positive cross-market bargaining effect provided $\sum_{h \in\left\{h_{1}, h_{2}\right\}} \Phi(\mathcal{G} \backslash h)>\Phi(\mathcal{G}) 18$

For ease of exposition, this example focused on the situation with a single employer and generated a stark prediction: a cross-market hospital merger will only generate a positive price effect if it creates a hospital system large enough that its removal causes the insurer to be dropped by the employer. However, in reality, insurers compete to be offered by multiple employers; furthermore, the prices and networks over which they bargain are not typically employer-specific. With a distribution of employers with heterogeneous employees and thresholds, there will generally be a non-zero impact of cross-market hospital mergers if at least some employers would be willing to switch insurers if a particular hospital system were dropped. The impact of cross-market mergers, thus, will typically increase with the importance of the combined system to employee welfare (relative to the welfare already generated by the underlying merging hospitals).

\subsection{Caveats and Limiting Factors}

What precludes any merger of suppliers to a common intermediary from enjoying an increase in market power? The key limiting factor to the common customer mechanism is the requirement that there exist a customer that, when choosing among intermediaries, places positive value on both merging suppliers. We view common customer effects as a natural extension of the horizontal theory underlying most merger challenges. However we note that, under some slightly amended versions of the model discussed above, these effects would not arise.

Inelastic Insurer Demand With Respect to the Network. A key component of the common customer effect in the hospital-insurer setting is the large reduction in the insurer's profits if it loses

\footnotetext{
${ }^{17}$ This extends the model in Ho and Lee (2017) to allow employers to drop an insurer if the "gains-from-trade" from employer-insurer bargaining are negative.

${ }^{18}$ An alternative justification for the link between markets can be derived from agency theory. Suppose the employer hires a single negotiator who deals with the insurer and who covers multiple markets. This negotiator has to report the results of his negotiations to the principal (his supervisor). He is able to report that a hospital has been dropped in one market, or the other, but may be fired if he loses both.
} 
the merged hospital system (relative to losing each hospital separately). In our example, this arose from an increased likelihood that employers would switch to other insurers. In settings, both within and outside of healthcare, where dropping an upstream merged entity is unlikely to affect the downstream intermediary's demand, there may be no price effects of cross-market mergers 19

Separable Demand by Common Customers. The simple model also assumed that employers faced a cost of offering additional plans. If instead employers could costlessly offer different plans in different markets, then markets would again be separable and no cross-market merger price effects would arise. However, insurers commonly design plans to cover broader geographic areas than most hospital service markets (Vistnes and Sarafidis, 2013), making this disaggregation difficult. We also note the empirical regularity that employers seem to prefer one-stop shopping. For example, CalPERS, an agency which provides pension and health benefits to California state and public employees, retirees, and their dependents, offers a single menu of plans across most markets in California.

Separable Bargaining. Our model assumes that hospital systems bargain jointly with each insurer. If systems bargain hospital by hospital, i.e. they cannot impose "all or nothing" requirements on insurers, then again the cross-market price effects will be removed. Anecdotal evidence, and estimates in papers such as Ho (2009) and Lewis and Pflum (2015), suggest that systems generally negotiate jointly, and often require insurers to include all system members in contracts.

\subsection{Other Cross-Market Mechanisms}

We now examine several situations where cross-market hospital mergers can generate price effects even though there are no customers who value both merging hospitals. Some of these effects may not constitute antitrust violations; in fact they may work in opposite directions, and in the aggregate may lead to post-merger quality-adjusted price reductions. Our empirical strategy aims to isolate these effects from the common customer effect described above.

"Common Insurer" Effects. We provide details of two mechanisms that require a common insurer-i.e., an insurer that operates in both markets and negotiates with both hospitals - but no common customer ${ }^{20}$ Under both mechanisms, a merged hospital system negotiating with a common insurer can negotiate higher (total) prices than would be possible under independent ownership.

\footnotetext{
${ }^{19} \mathrm{~A}$ dominant insurer negotiating with relatively small physician groups who are merging may be one example. Another may be the merger between Proctor \& Gamble and Gillette: although the two companies did not primarily compete with one another in any given product market, their merger may have provided them with an ability to negotiate better terms with retailers offering "one-stop" shopping services to households. However, it is plausible that consumers would not switch away from major retailers even if both firms' products were removed from its shelves, implying no increase in bargaining leverage, and no merger price effect.

${ }^{20}$ Our common customer effects also requires the presence of one or more common insurers negotiating with the merging parties.
} 
1. Price Cap in One Market. Consider a setting in which there is an independent hospital subject to a price cap due to political or regulatory restrictions. Suppose the cap binds so that the hospital is unable to increase its price to the level implied by Nash bargaining. In our model, this would imply that the first-order condition given by (2) is slack, and that the LHS of (2) is strictly less than the RHS. Consider now the effect of a merger between this hospital and another in a second market that is not subject to a price cap. If there is a common insurer that negotiates with both hospitals, (5) implies that the sum of the hospital prices will be a function of the hospital system's contributions to the insurer's revenues. As a result, by merging, the hospital subject to the price cap can generate an increase in the second hospital's negotiated prices so that the merged hospital system's Nash bargaining first-order condition given by (5) will bind. Thus the merger can yield a price effect due to the presence of a common insurer, even if the hospitals that merged were never valued by the same customers.

2. Linear Prices and Double Marginalization. Now consider a scenario where a monopolist insurer is active in two markets $A$ and $B$, there are monopolist hospitals active in each market, and negotiated prices are linear (i.e., per-patient payments). We show in Appendix C that, if premiums are set after linear fees are negotiated, then the double marginalization arising from the insurer's markup of the hospital's negotiated prices introduces an inefficiency from the perspective of the bargaining firms. There are potential industry profit gains from a hospital merger that allows the new combined system to internalize pricing effects across markets (e.g. by setting a lower price in markets with a relatively high elasticity of insurance demand and a higher price elsewhere) in a way that independent hospitals would not. The increase in industry surplus from internalizing these cross-market differences means that a hospital merger can increase the total payments made to the hospital system. However we conjecture that this effect is empirically less relevant than the common customer effect because it requires individual hospitals to sacrifice revenues for the benefit of other system members, and industry interviews suggest individual hospital CEOs are compensated and rewarded on the basis of their own facility's bottom line 21

Cost Savings, Bargaining Spillovers, and Co-insurance. Finally, a cross-market merger can generate cost savings, managerial improvements, or "bargaining spillovers"; each of these can affect prices. Cost efficiencies, for example due to the centralized provision of particular services, could lead to price reductions. Quality improvements or increases in bargaining ability or bargaining weight (as typically captured by the Nash bargaining parameter, and potentially arising from a reduction in hospital negotiators' risk aversion) could lead to price increases (Lewis and Pflum, 2015, 2016). If enrollees face coinsurance rates (so that the cost of visiting a hospital depends on the negotiated price), mergers may lead to a change in prices as insurers and hospitals respond to

\footnotetext{
${ }^{21}$ In the words of one former hospital system executive, "every tub on its own bottom" is the guiding principle when it comes to operating margins for each hospital.
} 
the impact of hospital pricing on utilization (Gowrisankaran, Nevo and Town, 2015) ${ }^{22}$ We consider all of these alternative explanations in our empirical analyses.

\subsection{Linking Theory to Empirics}

In the following section we present an empirical analysis of the price effects of cross-market mergers. We also conduct analyses to explore the potential mechanisms underlying the effects we uncover. We begin by describing three testable predictions of the "common customer" mechanism.

1. A necessary condition for a common customer effect is the existence of common insurers that operate in the markets of both the acquiring and the target hospital system. We explore this condition empirically by measuring the extent of insurer overlap across the merging hospitals and comparing the price effects of mergers between hospitals with higher and lower insurer overlap.

2. The price effect of a cross-market merger should be larger the more prevalent are common customers for the merging hospitals. We posit that mergers combining hospitals across different states or with greater distances between one another likely have fewer common customers. To test this prediction, we compare the estimated price effects for within-state ("adjacent") and out-of-state ("non-adjacent") treatments, and within the adjacent treatment sample, we consider whether the effects are increasing in the proximity of acquirers and targets.

3. Conditional on acquirer (target) size, the price effect on the acquirer is predicted to be increasing in the size of the target (acquirer). In order to generate an increase in negotiated prices through a common customer effect, a cross-market merger must create a sufficiently large and attractive hospital system that its loss from the network could plausibly induce employers or households to drop that plan. For a given acquirer size, mergers with larger target systems plausibly generate a larger increase in $\Delta W(\mathcal{M}, j)$ and therefore a larger price effect. Similarly, as acquirer size increases conditional on target size, the merger generates a larger $\Delta W(\mathcal{M}, j)$ and therefore a larger impact on price.

Remark. Distinguishing between mergers of substitutes and complements: We note in Section 2.2 that if the two merging systems are sufficiently strong complements, and reimbursement rates are determined via Nash bargaining both pre- and post-merger, then a merger may lead to a reduction rather than an increase in negotiated reimbursement rates. The sign of any estimated price effect is therefore an empirical question. Estimated price reductions following a merger may, under our common customer mechanism, indicate complementarities between the merging entities.

We also assess the empirical plausibility of the alternative mechanisms for cross-market price effects. Here are the key competing hypotheses and the empirical analyses that help us to assess the role they might play in generating the effects we document.

\footnotetext{
${ }^{22}$ The analysis in this case is similar to that related to linear prices and double marginalization; see below and Appendix C
} 
1. Cost efficiencies. As noted above, cross-market mergers may generate cost efficiencies, e.g. due to fixed costs of insurer-system negotiations or to operational efficiencies. For example, Dranove and Lindrooth (2003) find that merging hospitals that surrender a facility licenselikelier to happen if they are closer together-realize cost reductions. A recent study by Schmitt (2017) — utilizing the same data sources we use, but a broader set of merger types and a shorter time span - finds evidence of post-merger cost efficiencies for targets of crossmarket mergers, but not acquirers. To the extent cost efficiencies are present, they will offset (in whole or in part) the upward pricing pressure arising from market power effects.

2. Common insurer effects without common customers. The mechanisms described in Section 2.6 that require a common insurer but no common customer across two markets - involving a price cap or double marginalization under linear pricing - are likely to generate a price increase in one market but not the other ${ }^{23}$ A mechanism based on co-insurance rates, as in Gowrisankaran, Nevo and Town (2015), has a similar implication ${ }^{24}$ To the extent we find significant, positive price effects on average, these mechanisms are unlikely to explain that result. We further explore the significance of the "price cap" explanation by restricting the sample to acquiring hospitals only. If price effects persist in this sample, out-of-market acquisitions are not (on average) being undertaken so as to realize pre-existing market power of the acquirers via increasing the prices charged by targets.

3. Hospital investment in assets or quality. Mergers may be followed by significant investments that give rise to (pro-competitive, or competitively neutral) price increases. Any distancesensitive quality investments are likely to be focused on the target rather than the acquiring system. Hence, we again explore the robustness of our results to excluding all target hospitals (where the sample size allows, i.e. in the broad merger sample). We also consider the evidence for changes in service or customer mix among the remaining hospitals.

4. Transferable Bargaining Weight or Negotiating Skill. Merging parties may possess bargaining skill that is specific to a given insurer, and price increases could arise due to a transfer of this skill to the opposite party, or an increment associated with a merger (Lewis and Pflum (2015)). Because insurers tend to operate throughout a state, we expect this skill should not be sensitive to the within-state distance between merging hospitals. Thus, a finding of larger price effects for more proximate within-state merger partners would suggest bargaining spillovers are not the source. We perform this test by comparing price effects for same-state merging parties 30-90 minutes versus $90+$ minutes apart.

\footnotetext{
${ }^{23}$ In the setting with a binding price cap due to political constraints in one market, the hospital in the second, unconstrained market should experience a price increase, but that in the first is constrained by definition. The double marginalization scenario has the combined system setting a lower price in markets with a relatively high elasticity of demand and a higher price elsewhere.

${ }^{24}$ As noted in Gowrisankaran, Nevo and Town (2015), in a setting with coinsurance rates, the insurer "might be willing to trade off a lower price in the first market for a higher price in the second, in order to steer patients to or away from the outside option appropriately".
} 
5. Market Definition. Our broad sample analyses drop treatment hospitals gaining a system member within 30 minutes' drive because there may be within-market merger effects for these providers. If effective hospital markets are larger than these approximations, the estimated cross-market price effects will be upwardly biased. We repeat our analyses using the radius implied by a 45 minute drive time as a robustness test. Our limited data prevent us from extending the assumed market size further; however we note that hospital markets for antitrust enforcement are typically defined more narrowly than this.

\section{Empirical Analysis: Overview and Data}

We use data on hospital prices, system affiliations, and acquisitions to quantify the price effects of cross-market mergers in the hospital sector and to conduct the tests outlined in the previous subsection. Although we focus on cross-geographic-market hospital mergers, the conceptual arguments we assess pertain to cross-product-market mergers as well.

Our empirical strategy comprises three key elements: (i) identifying a set of hospitals whose involvement in a cross-market merger is plausibly exogenous to other determinants of hospital prices; (ii) among this set of "treatment hospitals," distinguishing between those gaining a system member nearby versus further away, as the common customer effect is likely stronger in the former case (the "further away" group should capture the aggregate effect of the other mechanisms described in Section 2.6); (iii) identifying a set of control hospitals that are not affected by any transactions over the relevant study period, and whose price trajectories are reasonable counterfactuals for the set of treatment hospitals. We estimate difference-in-differences models that compare price growth for two sets of "treatment" hospitals (specifically those gaining a system member in-state versus out-of-state) with price growth for "control" hospitals during the relevant time period. Below, we discuss our transaction samples and how we identify and categorize treatment hospitals.

\subsection{Defining Transaction Samples and Treatment Hospitals}

Prior research suggests that assuming hospital transactions and system affiliations are exogenous can lead to a significant underestimate of price effects. For example, using a set of one-to-one hospital mergers (i.e. mergers of independent hospitals), Dafny (2009) reports instrumental variable estimates of merger price effects in excess of 40 percent, whereas OLS point estimates for the same sample of transactions are near zero. Researchers have also found that new system affiliations are correlated with factors that also affect net prices 25

To help address the endogeneity of being party to a transaction, we focus on "bystanders" to transactions. The rationale is as follows: if a given hospital is not the driver of the transaction, and is merely "treated" by virtue of being part of an acquiring or target system, it is less likely

\footnotetext{
${ }^{25}$ Dafny and Dranove (2009) show that independent hospitals with poor operating performance and stronger "upcoding potential" are more likely to join for-profit hospital systems, and upon joining, to engage in upcoding that yields higher net revenues per admission.
} 
that the acquisition is the result of omitted factors correlated with price trajectories. We consider two sets of transactions: an FTC sample, and a broad (merger) sample.

FTC Sample. The FTC sample consists of mergers that were investigated by the FTC due to geographic overlap between the merging parties in one or more markets, and eventually consummated (with or without a legal challenge by the FTC) ${ }^{26}$ Table 1 lists the mergers in the FTC Sample and the geographic market with the closest overlap among the merging parties. Investigations are not typically announced by competition authorities unless a complaint is issued. However, private parties may disclose if they are under investigation or are being questioned in connection with an open investigation.

Combing public sources, we identified 23 investigations of proposed mergers among general acute care hospitals over the period 1996-2011 27 Of these 23 mergers, 3 were abandoned by the would-be merging parties, and 20 were consummated. Given the high costs associated with responding to an FTC investigation, we posit that these mergers were motivated by the combination of hospitals in an overlapping geographic market. Otherwise, the merging systems would likely have divested a potentially problematic property or abandoned the transaction in the face of FTC scrutiny. Hence, we consider the two hospitals closest to one another to be the "drivers" of each merger, and they are dropped from our primary analysis sample 28 We study the impact of the (consummated) merger on other system members that are part of the transaction. We argue that the treatment of gaining a system member is plausibly exogenous because the transaction generating the treatment was motivated by considerations related to a different (and omitted) set of hospitals. As a check of this assumption, we compare pre-merger price trends in treatment and control groups.

Figure 1 summarizes our strategy for identifying treatments using the FTC investigations. It depicts the merger of system A and system B across 3 states, represented by rectangles. Members of system A and B are both present in state 1, but were not the object of the FTC investigation. In state 2 , there is a clear potential horizontal overlap between the system members. In state 3 , only system B is present. Our approach is as follows: (i) we drop the two merging hospitals nearest one another in state 2; (ii) we designate all remaining members of systems A and B in states 1 and 2 as "adjacent treatment" hospitals; and (iii) we designate all members of system B in state 3 as "non-adjacent treatment" hospitals. For this sample, adjacent treatment hospitals are those

\footnotetext{
${ }^{26}$ Of the 20 consummated transactions in Table 1, five were challenged by the FTC (Tenet-Doctors Regional in Missouri, Butterworth-Blodgett in Michigan, ProMedica-St. Luke's in Ohio, Evanston Northwestern-Highland Park in Illinois, and Phoebe Putney-Palmyra Park in Georgia), and one by the California Attorney General (SutterSummit). In one additional transaction (the Tenet-OrNda merger of 1997), the merging parties agreed to divest a hospital located in the overlap market (French Hospital and Medical Center in San Luis Obispo, CA). As indicated in Table 1, of the transactions challenged or subject to a divestiture order, only Tenet-Doctors Regional, Sutter-Summit, and Tenet-OrNda are included in our estimation sample.

${ }^{27}$ In 2013, the FTC issued a report stating there were 20 total hospital merger investigations conducted between fiscal years 1996-2011, pursuant to the Hart Scott Rodino (HSR) Act. These figures include transactions among non-general acute-care hospitals, e.g. psychiatric hospitals. However, they exclude investigations of so-called "nonHSR reportable transactions." Nonprofits are subject to less stringent HSR reporting requirements, so in light of the fact that many hospitals are nonprofits, the aggregate totals appear to be well-aligned with this report. We did not include mergers taking place in 2012-2014 due to the absence of a post-period in our data on hospital prices.

${ }^{28}$ Where available, internet research confirms these are the hospitals generating FTC scrutiny.
} 
located within the same state but in different local markets (even if the local markets do not share a common border); non-adjacent treatment hospitals are those in the same system, but not in the same state. Table 1 reveals there are 10 transactions in the FTC Sample that generate treatment hospitals 29

Broad Sample. Given the small number of FTC-investigated transactions and other limitations we discuss below, we also consider a second, broader transaction sample. To create this second sample, we begin with all acquisitions and mergers involving general acute-care hospitals during the period 2002-2012, as identified by proprietary reports assembled by Irving Levin Associates, a company that gathers and sells data on transactions in a variety of sectors, including the U.S. hospital industry. As our strategy relies on examining the impact of a merger on bystander hospitals, we exclude mergers between independent hospitals. We impose two additional restrictions. First, we drop the "crown jewels" of each transaction, defined as the largest hospital being acquired for transactions involving five or fewer hospitals, and all hospitals above the 80th percentile of beds among target systems with more than five hospitals. Second, we drop hospitals gaining a system member within 30 minutes' drive, as there may be "same market" motivations and effects in these cases.

Our effort to focus on bystanders to a transaction is designed to minimize omitted variables bias. To the extent that transactions are motivated by crown jewels and/or within-market overlaps, then the impact of the transactions on other system members is plausibly exogenous to omitted determinants of price. While the transactions may be motivated in part (or in whole) by anticipation of price increases due to cross-market effects, our identifying assumptions require that they are not made in anticipation of unobserved cost or demand shocks that may themselves generate systematic price increases. As the largest assets in a transaction, the crown jewels of a target system seem likeliest to be acquired because of such unobserved (to the econometrician) shocks, hence we omit them (as well as the within-market overlaps).

In both samples, we investigate the potential for bias due to omitted factors by including leads for the transactions in our specifications; the coefficients on these leads will reveal whether treatment hospitals have pre-treatment price trends similar to those of control hospitals. While this test cannot rule out the possibility that price trends for bystanders and controls may subsequently diverge for unobserved reasons coincident with but independent of the merger, it still informs the plausibility of our identifying assumptions.

Figure 2 summarizes our strategy for identifying treatments using the broad merger sample, using as an example the 2007 acquisition of 4-hospital Baptist Health System (BHS) in Tennessee by Catholic Healthcare Partners (CHP), with 30 hospitals in and outside of Tennessee. The largest BHS hospital is dropped as the presumed acquisition target (crown jewel), and two BHS and one

\footnotetext{
${ }^{29}$ There are a number of reasons that all of the transactions in Table 1 cannot be included in the analysis sample. These include abandonment of the transaction, a merger between two independent hospitals (which, by definition, cannot generate effects on other system members), and ongoing litigation (inclusion of these would yield potentially downward-biased price effects as the merging parties have an incentive to avoid increasing price until all appeals are exhausted).
} 
CHP hospitals are dropped for being within 30 minutes of each other. This leaves three CHP and one BHS hospital in Tennessee as potential treatment hospitals. In our main analysis, we adopt the same convention as in the FTC Sample and use state boundaries to determine whether hospitals are considered to be within the adjacent or non-adjacent treatment groups. Thus, the four remaining hospitals in Tennessee are part of the the adjacent treatment group, while all CHP hospitals outside Tennessee are non-adjacent treatments. Note that this example illustrates all of our restrictions on a single transaction, however it is rare for target hospitals to survive the sample restrictions (as one did in this case). In Section 5, we consider alternative definitions for "adjacency," including a measure based on the shortest distance between merging hospitals (rather than state boundaries).

We next describe our data sources in greater detail and discuss descriptive statistics for our two estimation samples. We also explain how control groups are defined.

\subsection{Data}

We assemble data for three key purposes: (1) to calculate a measure of each hospital's price for commercially-insured patients and to obtain hospital characteristics that may be associated with price; (2) to build our two samples of transactions; and (3) to identify hospital system affiliations. We describe the sources for each of these objectives in turn.

We construct an estimate of hospital-year private prices using the Healthcare Cost Report Information System (HCRIS) dataset for fiscal years 1996-2012. HCRIS is a public dataset gathered by the Centers for Medicare and Medicaid Services (CMS). We follow the methodology in Dafny (2009), calculating private price as the (estimated) net revenue for non-Medicare inpatient admissions, divided by the number of non-Medicare admissions. Net revenue for non-Medicare inpatient admissions is estimated by multiplying gross charges for these admissions by the hospital's average revenue to charge ratio 3031 Unfortunately, the data do not permit us to exclude revenues for all non-commercially insured patients. As our models include hospital fixed effects, only variations in non-commercial, non-Medicare patient admissions and revenues could bias our estimates. Medicaid is the largest source of such patients, hence we include the percent of admissions accounted for by Medicaid patients as a control variable in our specifications ${ }^{32}$ Critical Access Hospitals and other hospitals not paid under Medicare's Prospective Payment System are excluded from the sample. While more precisely measured commercial prices would be preferable, HCRIS is the best-

\footnotetext{
${ }^{30}$ We make one modifcation to Dafny (2009), in that we include the Medicare case mix index for each hospital as an independent variable in our regressions rather than in the denominator of the price formula. More precisely, we define price $=[$ (hospital inpatient routine service revenue + hospital intensive care revenue + hospital inpatient ancillary revenue $)^{*}(1$-contractual discounts/total patient revenue) - Medicare primary payor amounts - Medicare total amount payable]/(total discharges excluding swing/SNF - total Medicare discharges excluding swing/SNF). All of these variables are separately reported in the HCRIS dataset. Observations with negative values for any measure in the price formula or discount factors greater than 1 are dropped, where discount factor=(1-contractual discounts/total patient revenue).

${ }^{31}$ We use data on all general acute care hospitals to construct percentiles of price, and then drop the $5 \%$ tails in each year. Across all years (1996-2012), the mean value (in CPI-adjusted year 2000 dollars) for the 5th percentile and 95 th percentile of price is $\$ 1,390$ and $\$ 12,966$, respectively.

${ }^{32}$ While HCRIS includes fields for Medicaid admissions and revenues, which would ideally be excluded, these fields are often empty or contain erroneous data.
} 
available source for national, time-series price data. Importantly, recent work by FTC economists finds price constructed from HCRIS is very highly correlated with price constructed from more detailed sources. For example, Garmon (2016) estimates a coefficient of 0.99 with an R2 of 0.90 when regressing casemix adjusted commercial inpatient prices calculated using financial data from PHC4 for Pennsylvania short-term GAC hospitals against commercial inpatient prices calculated using Healthcare Cost Report Information System (HCRIS) data and the Dafny (2009) formula.33 Garmon also reports a close relationship between area-level price changes derived from Truven data on actual insurance claims and the same price changes derived from the HCRIS data. Haas-Wilson and Garmon (2011) also study price changes for hospitals as part of a retrospective analysis of two hospital mergers. They report similar results using prices constructed from detailed claims data versus a combination of Cost Reports data and hospital discharge claims. These validations are particularly relevant for our study as all of our models rely on same-hospital price changes.

As previously described, we construct two datasets of general acute-care hospital mergers: one consisting of mergers investigated by the Federal Trade Commission over the period 1996-2011 (FTC Sample), and a second encompassing all mergers over the period 2002-2012 (Broad Sample). Additional information on each sample is presented in Table 1 and Table 2, respectively. The detailed breakdown in Table 1 reveals that only two transactions generate non-adjacent treatment hospitals: Tenet/OrNda in 1997 and Banner/Sun in 2008. Given that the HCRIS data begins in 1996, we have only one year of pre-merger price data for the Tenet/OrNda transaction, which is by far the larger of the two. In light of this, we view results from the non-adjacent treatment group in the FTC sample analysis as particularly tentative.

The Broad Sample is derived from a list of mergers involving general acute-care hospitals provided by Irving Levin and Associates. Table 2 presents descriptive information for the set of mergers that occurred between 2002 and 2012; these are the years for which we can construct an adequate pre and post-period. In all, there are 426 transactions, 332 of which generate adjacent and/or nonadjacent treatment hospitals. This larger sample size enables us to take more steps to ensure a clean treated sample than is possible when analyzing the FTC Sample. We limit our treatment sample to hospitals experiencing a treatment only once during the 5-year period spanning the transaction generating that treatment, i.e. all treatment hospitals must be exposed to no other mergers from $t=-2$ to $t=2$. We impose this restriction to ensure that the pre and post-treatment periods do not capture the effects of other transactions. Data for treatment hospitals that are "clean" for longer periods of time are included between $\mathrm{t}=-3$ up to $\mathrm{t}=4$, so as to expand our observation period 34

\footnotetext{
${ }^{33}$ The actual correlation for our version of price is likely to be lower, as Garmon uses CMI for commercial patients in his analysis. He does not report a result using the Medicare CMI, which we include as a control variable. We lack the detailed hospital-level claims data to do the same.

${ }^{34}$ We use supplemental Irving Levin data from 2000 and 2001, and manual checks for 2013-2014, to ensure that any "treated" hospitals are "clean" (i.e., untreated) for the 2 years before and after any merger included in our sample. Requiring a longer "clean" period for all treatment hospitals - i.e for the entire 8 year period in our regressions $(\mathrm{t}=-3$ to $\mathrm{t}=4$ ) - would exclude too many mergers from our sample. Of the 52 transactions with a clean treatment hospital from $\mathrm{t}=-2$ to $\mathrm{t}=2,35$ have a clean treatment hospital from $\mathrm{t}=-3$ to $\mathrm{t}=3$, and 27 have a clean treatment hospital from $\mathrm{t}=-3$ to $\mathrm{t}=4$. We could not impose this restriction in the FTC Sample because the largest of the two transactions generating treatments occurred in 1997 and we lack merger data in prior years.
} 
Relative to the set of all transactions, transactions that are included in our final analysis sample involve smaller acquirers (as measured by the number of facilities), since larger acquirers tend to engage in multiple closely-timed acquisitions. Unchanged is the median size of targets, which is a single hospital.

Table 3 displays descriptive statistics for adjacent and non-adjacent treatment hospitals in both samples (FTC and Broad). We also note the number of hospitals in each treatment group and sample that belong to the acquiring system versus the target system. Because the modal target in the Broad Sample is 1, the crown jewel restriction implies that few targets (just 6 hospitals in total) appear in the analysis sample. The results therefore largely reflect the impact of cross-market mergers on acquirers; as we suggested above this renders some alternative explanations unlikely. We report our main results with and without the 6 target hospitals; for ease of interpretation we drop them when estimating extensions to the main specifications.

Alongside the data on treatment hospitals we present summary statistics for both control groups. Control Group 1 consists of all hospitals not excluded due to same-market overlap (and not classified as treatments). Control Group 2 reflects the further restriction that control hospitals should be members of systems, and in the case of the Broad sample, that they not be located within 30 minutes of a treated hospital; if this occurs we drop the year of the treatment and the three following years.

Table 3 demonstrates that adding restrictions to the control group improves the comparability of the treatment and control samples at the cost of reducing the sample size. We estimate differencein-differences specifications using both samples and report the results below.

\section{Empirical Results: How Do Cross-Market Mergers Affect Hos- pital Prices?}

We quantify the impact on price of becoming an adjacent or non-adjacent party to a merger, relative to a sample of control hospitals over the same relevant time period. We estimate fixed-effects models of the following form:

$$
\ln \left(\text { price }_{h t}\right)=\alpha_{h}+\sum_{l} \phi_{l}^{a} \mathbb{1}_{h, t=m(h)+l}^{a d j}+\sum_{g} \phi_{g}^{n} \mathbb{1}_{h, t=m(h)+g}^{n a d j}+X_{h t} \theta+\tau_{t}+\varepsilon_{h t}
$$

where $h$ indexes hospitals, $t$ indexes years, and $m(h)$ denotes the year of the relevant transaction

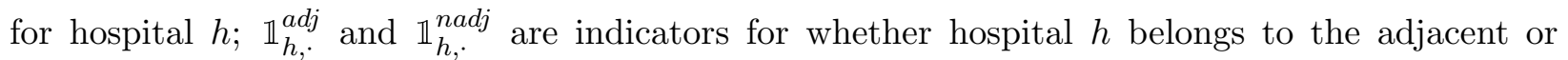
non-adjacent treatment group in the relevant year; and $X_{h t}$ are hospital characteristics including $\ln$ (case mix index), $\ln$ (beds), a for-profit ownership dummy, and percent of admissions to Medicaid enrollees. Given the inclusion of hospital and year fixed effects, coefficients on these variables are identified by within-hospital changes in these factors.

In our first specification, we include the maximum number of leads and lags permitted in each sample: for the reasons discussed in Section $3, l=-2 \ldots 4$ for both the FTC and the broad merger analysis, and $g=0 \ldots 4$ for the FTC analysis and $-2 \ldots 4$ for the broad merger analysis. The 
purpose of this model is twofold: first, to confirm the leads lack a pronounced trend (to support the contention that the price trajectory of the control hospitals is a reasonable counterfactual for the treatment hospitals absent the treatment); second, to examine how the price effect (if any) changes over time.

We also estimate a second specification where the treatment leads and lags are replaced with two variables for each treatment, an indicator variable for the year of the merger and another which takes a value of 1 in every subsequent year:

$$
\begin{gathered}
\ln \left(\text { price }_{h t}\right)=\alpha_{h}+\phi_{t=}^{a} \\
(h) \mathbb{1}_{h, t=m(h)}^{a d j}+\phi_{t>m(h)}^{a} \mathbb{1}_{h, t>m(h)}^{a d j}+\phi_{t=m(h)}^{n} \mathbb{1}_{h, t=m(h)}^{n a d j} \\
+\phi_{t>m(h)}^{n} \mathbb{1}_{h, t>m(h)}^{n a d j}+X_{h t} \theta+\tau_{t}+\varepsilon_{h t}
\end{gathered}
$$

Combining the post-merger years into a single dummy increases the precision of our estimates and provides a single point estimate for the price effect of each treatment. The specification allows for a different price effect in year $t=0$, as mergers may close at any point during the year in which they are recorded and hence $t=0$ does not strictly fall into the pre or post periods. In all regressions, observations are weighted by the hospital's number of discharges (averaged across all years), and standard errors are clustered by hospital

These models assume that treatment status is exogenous to omitted determinants of price. As previously described, our sample excludes hospitals that are the likely drivers of transactions. The rationale is that "bystanders" to transactions are unlikely to differ in unobservable ways from non-bystanders, i.e. control hospitals. Threats to identification are unobservable factors that differentially influence the negotiated prices for hospitals involved in mergers during the postmerger period versus hospitals in our control groups. For example, in the broad merger sample, hospitals that are never treated may have internally focused managers who are not entrepreneurial about seeking new partners and potentially less likely to negotiate steady price increases with payers (as most hospitals did throughout this time period). Alternatively, some merger targets may be chosen (based on unobservables) specifically to generate the cross-market price effects we seek to study. These unobservables will not bias our estimates unless they have a differential effect on price during the pre and post-acquisition period. To explore this concern we also estimate models in which we pair each treatment hospital with its closest match in the control group, as identified using a propensity score model. We then estimate a "differenced regression" that focuses on changes in price for each treatment relative to its closest match. As we discuss below, the results are broadly similar.

We now describe the results for each of the transaction samples in turn.

\footnotetext{
${ }^{35}$ Although all tables report standard errors with clustering at the hospital unit, the results are robust to clustering by transaction or by state.
} 


\subsection{FTC Sample}

The results from estimating equation (9) using the FTC-investigated merger sample are presented in Appendix Table 1. As discussed above, we report findings obtained using two control groups. Control Group 1 is very broad; Control Group 2 is restricted to hospitals that are system members and hence more similar to the treatment groups (which must be system members). The results are similar across the two samples. Figure 3 graphs the coefficient estimates on the leads and lags of the adjacent and non-adjacent indicator variable from equation (9) above, as estimated using Control Group 2. Beginning with the price patterns for adjacent hospitals, we see that price jumps up for these hospitals in $t=-2$ (relative to the omitted year, $t=-3$ ) by about 7 percent, and then holds steady until $t=0$. Prices increase steadily from $t=1$ to $t=4$, at which point the price of adjacent treatment hospitals is $17-18 \%$ higher than that of the control group, all else equal. Non-adjacent hospitals, for which we only have one year of pre-merger data, exhibit a statistically insignificant reduction in price in the year of the merger, after which prices fluctuate and ultimately end up slightly lower - albeit not significantly so - than where they started. We can reject equality of the coefficients on the adjacent and non-adjacent indicators in $t=4$ at $p<0.05$.

Most of the control variables have statistically significant coefficients. In both samples, increases in the complexity of a hospital's caseload, and in its number of staffed beds, are associated with higher prices. The for-profit dummy is also positive and statistically significant in both models. Given the inclusion of hospital fixed effects, the interpretation is that hospitals that convert to for-profit status experience price increases, all else equal. Changes in Medicaid patient share are not associated with significant changes in private price 36

Table 4 presents coefficient estimates from the parsimonious regression equation (10), in which we include indicators for $t=0$ and $t>0$ (separately for adjacent and non-adjacent treatment groups). The results show that the adjacent treatment leads to a statistically significant price increase of roughly 7 percent, while non-adjacent treatment is not linked to any significant price effects. The confidence interval around the non-adjacent treatment effect is very wide; this is unsurprising in light of the small number of transactions generating these treatments. As a result, we cannot reject equality of the adjacent and non-adjacent treatment effects in this sample. In addition, and as noted above, the treated hospitals experience a price surge between $t=-3$ and $t=-2$. Hence, we examine a broader set of transactions to corroborate these findings.

\subsection{Broad Sample}

The results obtained from estimating equation (9) using the Broad Sample are displayed in Appendix Table 2. Columns 1 and 2 correspond to control groups 1 and 2, respectively. The coefficients of interest are again insensitive to the choice of control group. Figure 4 plots the coefficients from the leads and lags of adjacent and non-adjacent indicators (relative to Control Group 2), and Table 5 presents results from the specification with a pooled post-period.

\footnotetext{
${ }^{36}$ As noted below, Appendix Table 4 reports results dropping all control variables, and they are very similar to the results including the controls.
} 
There is no significant evidence of pre-treatment trends in any of the models estimated. For both treatment groups the coefficients on $t=-2$ and $t=-1$ are very small and insignificant. Thereafter, price trends for the adjacent and non-adjacent groups diverge. The adjacent hospitals show steady price increases, with a particularly large jump between $t=2$ and $t=3$. The cumulative price increase is $14-15$ percent. By comparison, prices for non-adjacent treatment hospitals zigzag over time. All coefficients are negative but none are significantly different from zero and they end about 3 percent below their starting point (relative to controls). As we discuss below, dropping the target hospitals has virtually no impact on the estimates (results in column 3 of Appendix Table 2). The estimated coefficients on the control variables are comparable to those for the FTC-investigated sample.

The results in Table 5, which separate only $t=0$ and $t>0$, reveal that adjacent treatment is followed by a statistically significant price increase of roughly 10 percent. The point estimates for non-adjacent treatment hospitals during $t>0$ are small and negative, and never achieve statistical significance. Equality of the adjacent and non-adjacent treatment effects can be rejected at $p<0.05$ using both control groups.

\subsection{Robustness of Main Results}

We investigate the robustness of our results to alternative specifications. One possible concern regarding the FTC sample, given the small number of transactions in the data, is that the estimated price effects could be driven by a single merger. We repeat the main analysis excluding one merger at a time. The results are presented in Appendix Table 3. The estimates are very stable across these samples.

We also test the robustness of the results to inclusion of a for-profit indicator interacted with individual year dummies. Per Table 3 (Descriptive Statistics), treated hospitals in the FTC sample are far likelier to be for-profit than hospitals in either control group (in the broad sample, for-profit ownership is similar across the treatment group and Control Group 2). If for-profit hospitals have different price trajectories, then our estimated treatment effects could be reflecting this difference. However, the results (in Appendix Table 4, reported for both samples using Control Group 2) are exceedingly similar even allowing for different year effects for for-profit hospitals. We also estimate models excluding all control variables. The coefficients of interest, in columns 2 and 5 of Appendix Table 4, are virtually unchanged; this finding alleviates the concern that omitted, time-varying hospital and market characteristics that are correlated with price (as the controls are) are also correlated with treatment status.

Last, we develop a model that involves matching treatment hospitals to specific control hospitals. We estimate regressions analogous to those described above but replacing the variables with the differences between each treatment and its matched control(s). One advantage of this approach is that it admits heterogeneous time trends for different pairs of hospitals and matched controls.

The regression is below: 


$$
\ln \left(\text { price }_{h t} / \text { price }_{c(h), t}\right)=\alpha_{h}+\sum_{l} \phi_{l}^{a} \mathbb{1}_{h, t=m(h)+l}^{a d j}+\sum_{g} \phi_{g}^{n} \mathbb{1}_{h, t=m(h)+g}^{n a d j}+\left(X_{h t}-X_{c(h) t}\right) \theta+\varepsilon_{h t}
$$

We experimented with a variety of methods to determine the control hospital(s), denoted $c(h)$, for each treated hospital 37 The results obtained were very comparable to the results from the preferred specification: only adjacent hospitals increased price relative to matched controls ${ }^{38}$

\section{Disentangling the Sources of Price Increases From Cross-Market Mergers}

Our primary specifications reveal that cross-market mergers yield substantial price effects when those mergers involve hospitals in adjacent (same-state) markets. Section 2 suggests several mechanisms by which cross-market hospital mergers could lead to price increases. In this section we discuss specifications designed to elicit more direct empirical evidence of the common customer effect.

The Importance of a Common Insurer. The common customer effect requires that the merging hospitals negotiate with at least one common insurer, while alternative explanations (such as an increase in hospitals' bargaining skill or reduction in their negotiators' risk-aversion postmerger; cf. Lewis and Pflum (2015)) do not. We therefore investigate the importance of common insurers in generating a price effect. We create a measure of insurer overlap using CBSA-level market shares for comprehensive medical insurance, constructed from 2012 data from the National Association of Insurance Commissioners. We define insurers at the state level, e.g. Cigna in Texas is not pooled with Cigna in Oregon. Although insurers and health care providers do sometimes negotiate at regional and even national levels, within-state overlap of insurers is likely to be most relevant for the cross-market mechanisms we model.

The measure we define - insurer overlap - is hospital and transaction-specific, and continuous and monotonic in the degree of joint significance of the same insurers to a given treatment hospital and to the target system 39 To construct the overlap measure, we proceed in three steps. First,

\footnotetext{
${ }^{37}$ For example we used a match based on observables, matching controls (in control group 2) to treatments on the basis of Census division and urban/rural status, using several different numbers of matches (with or without replacement). We also used a method relying on a propensity score to find the closest match among potential control hospitals. The variables used to calculate the propensity score were the $\mathrm{X}$ variables included in the regression analysis, an indicator for urban areas, and measures of the number of other hospitals in the potential control's system. We encountered some sample size issues with both of these methods: the pool of potential matches for treatment hospitals was not large, and the same control hospital was quite frequently the best match for several treatment hospitals. However, the results were similar to the results obtained using the unmatched estimator.

${ }^{38}$ Results available upon request.

${ }^{39}$ For ease of interpretation, we drop the 6 treatment hospitals that are members of a target system. The results of doing so (for the pooled post-period model) are reported in column 3 of Table 5: there is very little change in the estimates.
} 
we compute the average market share of every insurer for each target system by taking the bedweighted average, across each of the system's hospitals, of each insurer's market share in that hospital's CBSA (or non-CBSA portions of the relevant state, if not located in a CBSA). Next, for each treatment hospital in our sample (which now consists solely of members of acquiring systems), we compare the vector of insurer market shares in that treatment hospital's CBSA (or non-CBSA portions of the state) with the vector of insurer average market shares for the target system. Our insurer overlap measure for a treatment hospital and transaction is the sum of the component-wise minimum across these two vectors.

The insurer overlap measure is bounded by 0 and 1 , equaling 0 if the treatment hospital and target system share no insurers, and 1 if they are located in the same CBSA. By definition, nonadjacent treatment hospitals (who gain a system member outside the state) are assigned a value of 0 for insurer overlap. The interquartile range is $[0.51,0.96]$, with a median of 0.82 . We estimate a specification that incorporates an interaction between the adjacent treatment effect and insurer overlap. (Because insurer overlap varies at the hospital level, we do not include it directly in the model as it is collinear with the hospital fixed effects.) The coefficient on the interaction term adjacent treated $*(t>0) *$ insurer overlap is positive but noisily estimated (point estimate 0.025, standard error 0.029). Importantly, it absorbs all of the merger price effect (i.e., the point estimate for the coefficient on the non-interacted term adjacent treated ${ }^{*}(t>0)$-around 0.10 without the interaction - is now negative and very imprecisely estimated with a point estimate of -0.09 and standard error 0.25). This constitutes suggestive evidence that insurer overlap is critical to generating post-merger price increases for adjacent treatment hospitals; unfortunately, we lack more precise data that would be ideal for testing our hypothesis (i.e., insurer market shares for each hospital and year).

The Role of Common Customers. We next investigate the impact of sharing common customers on merger price effects. We first attempt to construct hospital-specific measures of common customers for all treatment hospitals. An ideal measure of common customers would capture two factors: (i) the relative significance of employers who draw employees from both target and acquirer hospitals; (ii) the volume of employees who commute between both target and acquirer service areas. A proxy for factor (i) could be constructed using information on multi-site establishments and identifying which sites are in each hospital's primary service area. Regrettably, this information can only be acquired through on-site access to Census data, coupled with access to national hospital discharge data to construct hospitals' primary service areas. A second option is to use public data on commuting patterns between counties to capture factor (ii). The Census publishes such data using the American Community Survey as the primary source ${ }^{40}$ We considered two hospital and transaction-specific measures: an outflow-only measure (defined as the total share of county residents commuting to counties in which a hospital acquires a new system member), and an outflow

\footnotetext{
${ }^{40}$ The data are available at http://www.census.gov/population/metro/data/other.html. We use information on the number of commuters from county of residence to county of workplace, by county pair, averaged over the period 2006-2010.
} 
and inflow measure constructed as the sum of residents commuting between counties of hospitals newly linked via merger, divided by the number of county residents for the hospital in question plus inbound commuters. Unfortunately both variables are noisy measures of the extent to which the merging hospitals' service areas are linked by commuters. The commuter data are available only at the county level, and counties may be inaccurate measures of hospital service areas. In addition, these data do not capture relevant factors such as commuters' means of transportation and the extent to which family members also commute. Perhaps not surprisingly, interactions with our measures of commuter overlap do not enter significantly in our regressions.

We therefore pursue cruder measures of the role of commuters, by estimating models comparing the magnitude of the cross-market price effects for hospitals gaining members that are geographically closer versus further apart. The closer the hospitals in terms of drive time, the more likely employers are to have locations near both hospitals or to have employees who commute from the service area of one to the service area of the other. These realities will presumably make the employer less likely to choose an insurer that offers neither hospital than a plan that offers one but not the other; this preference generates the "common customer" price effect of a merger between the two hospitals.

We modify the regression in equation (9) by interacting the leads and lags for adjacent treatments with an indicator for mergers between hospitals located within 30-90 minutes' drive time of one another and an indicator for more distant merging hospitals (recall that we interpret mergers within 30 minutes' drive time as "horizontal" and therefore exclude them). We attempted to do the same for non-adjacent treatment hospitals, as the common customer effect could potentially transcend state boundaries, however we have too few merging hospitals that are 30-90 minutes apart but in a different state to enable a test of the importance of state boundaries ${ }^{41}$ The results from estimating this equation are presented in Appendix Table 5 and graphed in Figure 5. Only adjacent treatment hospitals gaining a system member within 30-90 minutes experience steady price increases throughout the study period. Adjacent treatments in the $90+$ category see small, imprecisely estimated price increases that tail off in $t=4$. Four years after gaining a nearby system member, prices for the 30-90 group are 19\% higher than the controls, compared to a (statistically insignificant) $3 \%$ higher and 3\% lower for the $90+$ adjacent treatments and non-adjacent treatments, respectively. Pooling across the entire post-merger period, we can reject equality of the 30-90 coefficient and the non-adjacent treatment coefficient. We interpret these findings as consistent with the existence of common customer effects.

The Impact of Acquirer and Target Size. In section 2.7, we outline the theoretical predictions regarding acquirer and target size. To test these hypotheses, we add interactions between the adjacent $*(t>0)$ term (the "post-treatment dummy") and two separate indicators, one for "above median" acquirer size and the second for "above median" target size, where size is measured as market share of all beds in the (same-state) CBSAs where either or both acquirer and target operate.

\footnotetext{
${ }^{41}$ The 104 hospitals in the adjacent treatment group are roughly evenly split between 30-90 and 90+ minutes. Only 7 of the 55 hospitals in the non-adjacent treatment group are in the 30-90 minute category.
} 
We also include a triple interaction between the post-treatment dummy and both size indicators; the coefficient on this interaction will isolate the difference in price effects for hospitals where both merging parties are relatively large. For ease of interpretation, we exclude all target hospitals from the estimation sample. Collectively, these variables isolate the effects of mergers on the four combinations of acquirer size indicator and target size indicator. The results are reported in Table 6. Beneath the coefficient estimates we present linear combinations of the relevant coefficients (and associated standard errors). Price increases are statistically significant for 3 of the four groups. Consistent with the predictions of our model (laid out in section 2.7), we find that small acquirers raise price more following the acquisition of a large (relative to a small) target. Further, and again consistent with the theory, the price effect of purchasing a small target is increasing in acquirer size. (Note that the median acquirer share is 0.14 , whereas the median target share is 0.07 , so below-median acquirers in this sample are not "small," considering the large geographic territory spanned by the union of CBSAs in which the target and/or acquirer operate.) We do not see price effects when large acquirers purchase large targets. This result is consistent with greater cost efficiencies of such transactions, or with complementarities among the two systems (e.g., employers refuse to purchase plans without either ex ante).

Other Dimensions of Heterogeneity. We also estimated specifications that explored other dimensions of merger heterogeneity. For example we investigated whether merger price effects differed with the service lines offered by the merging systems; the initial price level of target or acquiring system or the difference between them; or with hospital market structure. However, while theory predicts heterogeneity in merger price effects due to variation in hospital characteristics and market structure, it was unfortunately difficult to capture such heterogeneity given our small final transaction sample.

Alternative Explanations. The results thus far are consistent with the acquisition and exercise of post-merger market power by acquirers of hospitals operating in the same state. The effects are stronger when the merging parties are closer to one another (and hence likelier to share common customers) and appear to increase with the extent of insurer overlap. The net positive estimated price effects indicate that, on average, merging entities in our sample are substitutes rather than complements, with the exception of transactions between large acquirers and large targets. The results are also inconsistent with the alternative hypotheses enumerated in section 2.7. First, cost efficiencies arising from lower negotiation costs with insurers and post-merger operational efficiencies do not appear to outweigh price-increasing effects, at least among in-state transactions. Second, mechanisms that operate through common insurer effects absent common customers (e.g., via coinsurance rates) are unlikely to yield sizeable net positive price effects, nor should these effects decrease in the distance between the merging parties.

The alternative explanations numbered 3-6 merit further discussion. Alternative explanation 3 refers to the possibility that mergers are followed by significant investments that drive price increases. We explore this alternative explanation in two ways: first, we confirm the results are 
robust to dropping targets entirely, as operational and strategic changes are likeliest for these hospitals. The coefficients of interest (reported in column 3, Table 5) are virtually unchanged. Second, we estimate models using CMI and Medicaid patient shares as dependent variables (results available upon request). We find precisely estimated coefficients close to zero for both treatment groups and dependent variables. For ease of exposition, in the extensions that follow we continue to drop target hospitals from the estimation sample.

Alternative explanation 4 is the possibility that acquirers raise price by virtue of gaining access to the target's superior bargaining skill or due to an increase in bargaining weight arising from increased system size, as emphasized in Lewis and Pflum (2015). This hypothesis would not explain the stronger effects we see for mergers within 30-90 minutes' drive, as most insurers operate statewide. Notwithstanding this observation, we note that our empirical approach probably skews us away from identifying an effect due to transfer of bargaining skill across hospitals. Unlike Lewis and Pflum (2015), who analyze price effects for stand-alone hospitals that are purchased by out-of-market systems, our estimation sample focuses on acquiring systems. We explicitly exclude standalone hospitals, as we analyze bystander hospitals to each transaction. Acquiring systems in our sample are large relative to targets. If bargaining skill is increasing in system size, as Lewis and Pflum (2015) hypothesize, this implies that acquirers in our data are unlikely to gain substantial new bargaining skill from the mergers we study ${ }^{42}$ Thus our results can be viewed as complementary to those in Lewis and Pflum (2015). We provide evidence of merger price increases consistent with common customer effects, while that paper focuses on a different data sample that highlights the possibility that stand-alone hospitals, when acquired by large systems, can experience price increases consistent with improved bargaining skill.

Alternative explanation 5 for our results is that they capture horizontal rather than crossmarket effects. To evaluate this possibility, we consider two supplemental analyses. First, we use a "same-market" definition of 45 minutes, rather than 30, for the broad sample. The 45-minute driving radius definition causes many treatment hospitals to be dropped, as we exclude withinmarket merging hospitals (as well as all hospitals in the control group located within the same distance of any of these overlapping treatment hospitals). The estimated treatment effect is of similar magnitude (i.e. nearly a 10 percent price effect using both control groups), suggesting that the cross-market effect is present even when horizontal market boundaries are large - although it is estimated much less precisely $(\mathrm{p}$-values $<0.15)$. These results suggest the magnitude of the effects are not larger for hospitals likelier to be substitutes for the same set of patients.

Second, we look directly at whether the hospitals with same-market overlap (i.e. those we drop in our main analysis) exhibit price increases; to the extent they do, it is more likely that our cross-market estimates reflect some horizontal (within-market) effects. The estimated price effect for hospitals dropped from the FTC sample due to same-market overlap is small and negative (and

\footnotetext{
${ }^{42}$ Lewis and Pflum (2015) reports that, for every 10 additional hospital members of a (not-for-profit) hospital system, the members extract an additional 8-9 percent of surplus from their contracts with insurers. Assuming no change in costs, the implied impact on acquirer price of the modal acquisition (one hospital) is 0.8-0.9 percent, a figure much smaller than our estimated 10 percent price effect on acquirers.
} 
statistically indistinguishable from zero). We interpret this result as consistent with appropriate enforcement activity (i.e., either the merger efficiencies outweighed any potential anticompetitive effects or the hospitals were not close substitutes ex ante), or with the possibility that the scrutiny of various stakeholders impacted post-merger price negotiations. In the broad sample, we note that only 5 hospitals exist in the "horizontal overlap" group, because the median target system size is one and we always exclude the largest target hospital from our analysis. Among these 5, we observe a price increase, but only in the year of acquisition. After this year, price is no longer statistically different from the pre-merger years. Given the small sample size, we are loath to draw conclusions from this analysis ${ }^{43}$ Overall, our analyses do not suggest we are capturing horizontal effects of the set of mergers we investigate, at least when the product market is hospital services delivered to commercially-insured patients (as opposed to the market we propose, i.e. the market for inclusion in an insurer's network of healthcare providers).

\section{Concluding Remarks}

This study provides theoretical and empirical analyses of the price effects of cross-market mergers of upstream suppliers to intermediaries who bundle and sell their services. Our model emphasizes the ways in which cross-market mergers differ from within-market mergers, setting aside commonalities shared across both merger types - such as changes in bargaining skill, managerial practices, service mix, and costs. The theory demonstrates that price changes (both positive and negative) may arise when the merging parties negotiate with a common buyer, and customers of that buyer value both parties (i.e., their demand for the bundle is influenced by the inclusion of the parties). We also discuss alternative explanations for how prices can change even absent these common customers.

Using data on two distinct samples of transactions - and focusing on "bystander" hospitals that are not likely to be the drivers of the transactions and are thus arguably exogenously treated - we compare price effects of gaining a system member in-state versus out-of-state. We find that hospitals acquiring another system member in-state raise price by 7-10 percent, whereas an acquisition outof-state does not result in a statistically meaningful change in price. Further analyses provide suggestive evidence that mergers of proximate hospitals (i.e. within 30-90 minutes' drive, in state) lead to the largest price effects. These are precisely the sort of cross-market hospital mergers where common customers are likeliest to be present. We interpret these results as consistent with the presence of a common customer effect that is driving post-merger price increases. We also show the results are similar when dropping target hospitals, which suggests that changes to a target's operations are not the driver of the estimated price effects. Last, we find no changes in case mix or Medicaid patient share for acquirers, as might be expected if acquirers reposition themselves in

\footnotetext{
${ }^{43}$ Our sample is not designed to study the effects of same-market overlap, and these results should not be viewed as inconsistent with the large literature that finds mergers of close substitutes in the same patient market yield substantial price increases. In particular, we do not include any one-to-one mergers as they lack bystanders, and we require merging parties to engage in only one such transaction (nationwide) over a given 5-year period so that we can have a clear pre and post-treatment period. Our results likely also reflect our crude horizontal market definition, as well as appropriate enforcement activity.
} 
terms of services offered and customer segments.

Prior researchers have shown that mergers of nearby, similar rivals can lead to increases in market power and higher prices. The existence of a common customer effect implies that market power may arise from combinations over even broader geographic areas and across product markets. This finding does not imply more expansive boundaries for mechanical calculations of market shares and " $\triangle H H I$ "s used to evaluate whether mergers are likely to be anticompetitive; rather, we believe it favors an emphasis on the "direct effects" likely to arise from a merger, a concept promulgated in the 2010 Horizontal Merger Guidelines. The results do suggest that combinations across broader areas should be carefully evaluated by antitrust authorities, particularly if customers (such as employers) value insurance products containing both merging parties, if there is significant commuting between the areas where the merging parties are located, and/or if the same insurers are dominant.

Cross-market mergers are an increasingly relevant phenomenon in the U.S., and particularly in the healthcare landscape. The theoretical and empirical analyses in this study illustrate that at least some of the mechanisms by which cross-market hospital mergers generate price increases are related to a diminution of competition among the merging parties for inclusion in insurer networks, and are therefore relevant for antitrust enforcement. Additional research that explicitly models the links between and among insurance choice, insurance competition, and hospital-insurer bargaining could prove valuable to antitrust enforcers and others interested in fostering and protecting competition in healthcare markets.

\section{References}

Capps, Cory, David Dranove, and Mark Satterthwaite. 2003. "Competiton and Market Power in Option Demand Markets." RAND Journal of Economics, 34(4): 737-763.

Chipty, Tasneem, and Christopher M. Snyder. 1999. "The Role of Firm Size in Bilateral Bargaining: A Study of the Cable Television Industry." Review of Economics and Statistics, 81(2): 326-340.

Collard-Wexler, Allan, Gautam Gowrisankaran, and Robin S. Lee. forthcoming. "'Nashin-Nash' Bargaining: A Microfoundation for Applied Work." Journal of Political Economy.

Crawford, Gregory S., and Ali Yurukoglu. 2012. "The Welfare Effects of Bundling in Multichannel Television Markets." American Economic Review, 102(2): 643-685.

Dafny, Leemore S. 2009. "Estimation and Identification of Merger Effect: An Application to Hospital Mergers." Journal of Law and Economics, 52(3): 523-550.

Dafny, Leemore S., and David Dranove. 2009. "Regulatory Exploitation and Management Changes: Upcoding in the Hospital Industry." Journal of Law and Economics, 52(2): 223-250.

Dranove, D., and W.D. White. 1994. "Recent Theory and Evidence on Competition in Hospital Markets." Journal of Economics and Management Strategy, 3(1): 169-209. 
Dranove, David, and Richard Lindrooth. 2003. "Hospital consolidation and costs: another look at the evidence." Journal of Health Economics, 22(6): 983-997.

Easterbrook, Kathleen F., Gautam Gowrisankaran, Dina Older Aguilar, and Yufei Wu. 2017. "Accounting for Complementarities in Hospital Mergers: Is a Substitute Needed for Current Approaches?" University of Arizona.

Farrell, Joseph, David J. Balan, Keith Brand, and Brett W. Wendling. 2011. "Economics at the FTC: Hospital Mergers, Authorized Generic Drugs, and Consumer Credit Markets." Review of Industrial Organization, 39: 271-296.

Garmon, Chris. 2016. "The Accuracy of Hospital Merger Screening Methods." Federal Trade Commission Bureau of Economics Working Paper 326.

Gaynor, M., and W. B. Vogt. 2003. "Competition Among Hospitals." RAND Journal of Economics, 34(4): 764-785.

Gaynor, Martin, and Robert Town. 2012. "The Impact of Hospital Consolidation: Update." Princeton, NJ: Robert Wood Johnston Foundation.

Gaynor, Martin, Kate Ho, and Robert J. Town. 2015. "The Industrial Organization of Health Care Markets." Journal of Economic Literature, 53(2): 235-284.

Gowrisankaran, Gautam, Aviv Nevo, and Robert J. Town. 2015. "Mergers When Prices Are Negotiated: Evidence from the Hospital Industry." American Economic Review, 105(1): 172203.

Grennan, Matthew. 2013. "Price Discrimination and Bargaining: Empirical Evidence from Medical Devices." American Economic Review, 103(1): 147-177.

Haas-Wilson, D., and C. Garmon. 2011. "Hospital Mergers and Competitive Effects: Two Retrospective Analyses." International Journal of the Economics of Business, 18(1): 17-32.

Ho, Kate, and Robin S. Lee. 2017. "Insurer Competition in Health Care Markets." Econometrica, 85(2): 379-417.

Ho, Katherine. 2006. "The Welfare Effects of Restricted Hospital Choice in the US Medical Care Market." Journal of Applied Econometrics, 21(7): 1039-1079.

Lewis, Matthew S., and Kevin E. Pflum. 2015. "Diagnosing Hospital System Bargaining Power in Managed Care Networks." American Economic Journal: Economic Policy, 7(1): 243271.

Lewis, M.S., and K.E. Pflum. 2016. "Hospital Systems and Bargaining Power: Evidence from Out-of-Market Acquisitions." RAND Journal of Economics. Conditionally accepted. 
Peters, Craig T. 2014. "Bargaining Power and the Effects of Joint Negotiation: The "Recapture Effect"." DOJ Discussion Paper.

Schmitt, Matt. 2017. "Do Hospital Mergers Reduce Costs?" Journal of Health Economics, 52: 7494.

Town, Robert J., and Gregory Vistnes. 2001. "Hospital Competition in HMO Networks." Journal of Health Economics, 20: 733-753.

Villas-Boas, Sofia B. 2007. "Vertical Relationships between Manufacturers and Retailers: Inference with Limited Data." Review of Economic Studies, 74(2): 625-652.

Vistnes, Gregory, and Yianis Sarafidis. 2013. "Cross-Market Hospital Mergers: A Holistic Approach." Antitrust Law Journal, 79: 253-291. 


\section{A Willingness to Pay (WTP) for an Insurer's Network}

In this section, we define the "willingness-to-pay" of an individual for the insurer's network of hospitals $\mathcal{G}$, represented by $W T P(\mathcal{G}) . W T P$ is typically used as an argument in the insurer's objective function $\Phi$ when the insurer bargains with hospitals.

The literature (e.g., Town and Vistnes, 2001; Capps, Dranove and Satterthwaite, 2003, Ho, 2006) derives WTP from a simple model of individual demand for hospitals typically as follows. Suppose that the utility of a given individual $p$ from visiting hospital $i$ given diagnosis $l$ is:

$$
u_{p, i, l}=\delta_{i}+z_{i} v_{p, l} \beta+\varepsilon_{p, i, l}
$$

where $\delta_{i}$ is the average quality of the hospital, $z_{i} v_{p, l}$ are interactions between observed hospital and individual characteristics (which may vary by diagnosis $l$ ) and $\varepsilon_{p, i, l}$ is an i.i.d. logit error term. This model generates a simple expression for individual $p$ 's expected utility from the hospitals in the insurer's network for diagnosis $l\left(E U_{p, i, l}\right)$. These values are then weighted by the probability that individual $p$ is admitted to a hospital and diagnosed with $l\left(\gamma_{p, l}\right)$ to obtain the expected WTP for that individual:

$$
W T P_{p}(\mathcal{G})=\sum_{l} \gamma_{p, l} E U_{p, i, l}(\mathcal{G})
$$

Furthermore, we denote by $\Delta W T P_{p}(\mathcal{G}, h) \equiv W T P_{p}(\mathcal{G})-W T P_{p}(\mathcal{G} \backslash h)$ the change in individual $p$ 's $W T P$ for an insurer's network if that insurer loses access to hospital $h$. Similarly we define $\Delta W T P_{p}(\mathcal{G}, \mathcal{S})$ for any hospital system $\mathcal{S}$.

Merger Effects on $\triangle W T P . \quad$ First, note that if $h_{1}$ and $h_{2}$ compete for the same individual within the same geographic market $m$ and diagnosis $l$, it will generally be the case (e.g., with logit utility for hospitals) that:

$$
\Delta W T P_{p}(\mathcal{G}, \mathcal{S})>\sum_{h \in\left\{h_{1}, h_{2}\right\}} \Delta W T P_{p}(\mathcal{G}, h)
$$

where $\mathcal{S} \equiv\{1,2\}$. This arises from the non-linearity in $E U_{p, i, l}$ and substitutability of the hospitals. For intuition, note that if the insurer drops only hospital 1, this may reduce $W T P$ very little since customers can substitute to hospital 2; however, if the two hospitals merge, and there is no other close substitute in the market, dropping the combined hospital system $\mathcal{S}$ reduces customer $W T P$ by a greater amount. Thus, the impact of the loss of hospital 1 to the WTP for an insurer's network will be greater if 2 is also absent from the network if hospitals 1 and 2 are substitutes (Capps, Dranove and Satterthwaite (2003)).

However, if hospitals 1 and 2 do not compete for the same individual - either because the hospitals are located in different geographic markets or because they serve different diagnosesthen (13) will not hold. Instead, it will be the case that $\Delta W T P_{p}(\mathcal{G}, \mathcal{S})=\sum_{h \in\left\{h_{1}, h_{2}\right\}} \Delta W T P_{p}(\mathcal{G}, h)$

and the change in an insurer's $W T P$ from losing both hospitals will simply be the sum of the change in the insurer's WTP from losing each individual hospital. 


\section{B Insurance Demand with Cross-Market Price Effects}

In Section 2.4 we note that if households, rather than individuals, choose insurers based on a utility equation that includes the sum of household members' $W T P$ for the hospital network, this may generate links across diagnostic markets that can generate price effects of cross-diagnostic market hospital mergers. We now provide another example.

Assume an insurer's objective function is equal to its profits, and that profits can be represented by $\Phi=D(\cdot) \times(\phi-\eta)$, where $D$ is the demand for the insurer's product, and $\phi$ and $\eta$ are per-enrollee premiums and insurer non-hospital costs 44 Assume in addition, for ease of exposition, that the margin per enrollee is invariant to the negotiated hospital network. Substituting this formulation for $\Phi$ into our necessary condition for a hospital merger to have a positive price effect ((6)) yields:

$$
[D(\mathcal{G})-D(\mathcal{G} \backslash \mathcal{S})]>\sum_{h \in\left\{h_{1}, h_{2}\right\}} D(\mathcal{G})-D(\mathcal{G} \backslash h)
$$

(where, if the inequality were reversed, the price effect would be negative). Thus, a sufficient condition for hospitals $h_{1}$ and $h_{2}$ to benefit from a merger despite being in different (geographic or product) markets would be for the change in demand for the insurer when both hospitals are dropped together to exceed the sum of changes in enrollment when each is dropped individually.

The "concavity" of demand for an insurer's product in the utility generated by its network, represented by (14), can arise whenever the merging hospitals have one or more common customers. Consider a stylized setting where an insurer competes against an outside option (e.g., not purchasing insurance or purchasing plans offered by other insurers). This insurer delivers utility to customer $c$ given by $v=g(\cdot)+W T P^{c}(\mathcal{G})$, where $g(\cdot)$ is some function of insurer and market characteristics. Furthermore, assume that the insurer has captive enrollees who would not switch to the outside option (which delivers some utility $v_{0}$ ) unless they are subjected to a reduction in utility that is large enough to outweigh the switching costs. In this case, if only hospital $i$ or $k$ were dropped by the insurer, a customer may not find it worthwhile to leave the insurer, and thus the insurer's loss in profits from disagreement with either $i$ or $k$ would be minimal. If, however, both hospitals were excluded from the insurer's network, then customers may find it worthwhile to switch to a competing insurer (or outside option). Thus, the presence of switching costs may also generate the necessary concavity in the insurer's objective function.

Whether (6) holds will depend not only on the properties of demand for insurers, but also on how the margins per enrollee are determined (which, for simplicity, we have assumed fixed). Adding these considerations or other complexities (e.g., choice set variation, informational frictions, etc.) to the model may change the precise behavior of $D$, but are unlikely to restore the linearity of the insurer's objective $(\Phi)$ in the utility of its network $(W T P)$. More generally, we observe that moving from the simple linear insurer objective function assumed in earlier models to a more realistic function reflecting insurer profits generates non-linearities in $W T P$ quite easily, and this is

\footnotetext{
${ }^{44}$ Ho and Lee (2017) contains a general analysis of this type of model.
} 
all that is needed for cross-market price effects (the direction of which, as noted in the main text, is theoretically ambiguous).

\section{A Common Insurer Effect with Linear Fees}

In our second example, we examine the potential for a cross-market merger between hospitals to generate a price effect when negotiated prices are linear (i.e., per-patient payments) and at least one insurer operates in both markets.

Consider a monopolist insurer that is active in two markets, $A$ and $B$, and suppose that there are monopolist hospitals active in each market. Assume that the insurer's profit in each market $m \in$ $\{A, B\}$, if it has an agreement with the hospital in the market, is given by $\Phi_{m}=D_{m}\left(\phi_{m}\right) \times\left(\phi_{m}-p_{m}\right)$ where $D_{m}$ represents the demand for the insurer, $\phi_{m}$ is the insurer's premiums, and $p_{m}$ is now a (linear) per-enrollee price negotiated with the hospital in that market for hospital services 45 Thus, each hospital's profit upon agreement is given by $\pi_{m}=D_{m} p_{m}$. For simplicity, we assume away fixed and marginal costs; including them will not change the result. We also assume that the insurer and hospital in each market do not obtain any demand or profits without agreeing to a contract: i.e., the disagreement point from bargaining for both parties is 0 .

Finally, we assume that premiums are set in each market after bargaining over hospital prices concludes. Thus, the premiums that the insurer sets in each market will satisfy:

$$
\phi_{m}^{*}=\arg \max _{\phi} D_{m}(\phi)\left(\phi-p_{m}\right)
$$

If the hospitals are not merged, prices in each market are assumed to satisfy the following asymmetric Nash Bargain:

$$
p_{m}^{*}=\arg \max _{p}\left[D_{m}\left(\phi_{m}^{*}(p)\right)\left(\phi_{m}^{*}(p)-p\right)\right]^{1-b} \times\left[D_{m}\left(\phi_{m}^{*}(p)\right) p\right]^{b} \quad m \in\{A, B\}
$$

where $\phi_{m}^{*}(p)$ represents the solution to (15) for a given negotiated price $p$. The FOC of (16) can be expressed as:

$$
\frac{\Lambda_{m} p_{m}}{D_{m}(\cdot)}=\frac{p_{m}-b \phi_{m}^{*}(p)}{b\left(\phi_{m}^{*}(p)-p_{m}\right)} \quad m \in\{A, B\}
$$

where $\Lambda_{m}=\left(\partial D_{m} / \partial \phi_{m}\right)\left(\partial \phi_{m} / \partial p_{m}\right)$ and represents the change in the insurer's demand due to an increase in its premiums brought on by an increase in the negotiated price (i.e., the effect on demand of pass-through).

On the other hand, if the two hospitals merge and prices are jointly negotiated to maximize:

$$
\left\{p_{A}^{M, *}, p_{B}^{M, *}\right\}=\arg \max _{p_{A}, p_{B}}\left[D_{A}(\cdot)\left(\phi_{A}^{*}\left(p_{A}\right)-p_{A}\right)+D_{B}(\cdot)\left(\phi_{B}^{*}\left(p_{B}\right)-p_{B}\right)\right]^{1-b} \times\left[\left(D_{A}(\cdot) p_{A}+D_{B}(\cdot) p_{B}\right)\right]^{b}
$$

\footnotetext{
${ }^{45}$ For exposition and to simplify notation, we assume that the hospital is paid for all enrollees. Assuming that only some fraction of enrollees visit the hospital, and that the hospital is reimbursed only for those enrollees that visit, does not affect the spirit of the following analysis.
} 
then the FOCs of (18) can be expressed as:

$$
\frac{\Lambda_{A} p_{A}}{D_{A}(\cdot)}=\frac{\Lambda_{B} p_{B}}{D_{B}(\cdot)}=\frac{\left[\left(D_{A}(\cdot)\left(p_{A}-b \phi_{A}^{*}\left(p_{A}\right)\right)+D_{B}(\cdot)\left(p_{B}-b \phi_{B}^{*}\left(p_{B}\right)\right)\right]\right.}{b\left[D_{A}(\cdot)\left(\phi_{A}^{*}\left(p_{A}\right)-p_{A}\right)+D_{B}(\cdot)\left(\phi_{B}^{*}\left(p_{B}\right)-p_{B}\right)\right]}
$$

The left-hand-sides of both (17) and (19) correspond to the elasticity of (insurer) demand with respect to the negotiated price. Consider two cases:

1. If $\Lambda=0$ so that these elasticities are 0 - as in the case where premiums are set before or simultaneously with negotiated prices, or prices are lump sums as opposed to linear-then the prices that satisfy the non-merged Nash bargaining FOCs given by (17) would also satisfy the merged Nash bargaining FOCs in (19). In such a setting, without a merger, prices in each market would be $p_{m}^{*}=b \phi_{m}^{*}$, i.e., negotiated prices would be a fraction $b$ of the fixed premiums; with a merger, prices $\sum_{m} D_{m} p_{m}^{*}=b \sum_{m} D_{m} \phi_{m}^{*}$, i.e. total payments to the merged entity would be the same fraction $b$ of total insurer revenues across both markets. Although a merger could thus result in a change in prices across markets (higher in one, lower in another), total payments to the hospitals would be unchanged and there would be no merger price effects (although distributional effects may arise).

2. On the other hand, if $\Lambda_{m} \neq 0$ - which generally will be the case when premiums are set after linear fees are negotiated 46 the total prices that are negotiated to satisfy (17) need not be the same as those negotiated to satisfy (19). Note that the merged Nash bargaining FOC in (19) requires that the elasticities of demand with respect to the negotiated prices across both markets $m \in\{A, B\}$ are equalized, whereas this need not be the case absent a merger. Indeed, insofar as an inefficiency is introduced (from the perspective of the insurer and hospitals) by the double marginalization arising from the insurer's markup of the hospitals' negotiated prices, there are potential industry profit gains from having a hospital system internalize the pricing effects across markets. For example, if the magnitude of the elasticity of demand with respect to $p_{A}^{*}$ (in market $A$ ) is greater than the elasticity of demand with respect to $p_{B}^{*}$ (in market $B$ ), so that a price increase in market $A$ would lead to a larger reduction in demand than in market $B$ at the negotiated prices when the hospitals are independent, then a merged hospital system would wish to adjust its prices to set a lower $p_{A}^{M \text {,* }}<p_{A}^{*}$ and offset this with a higher $p_{B}^{M, *}>p_{B}^{*}$. Due to the increase in industry surplus from internalizing these cross-market differences, a hospital merger can increase the total payments made to the hospital system.

The key to generating this type of cross-market merger price effect absent a common customer is the existence of an inefficiency from the perspective of the bargaining firms-i.e. double marginalization due to linear fees. Mitigating this inefficiency via a hospital merger can leave both the

\footnotetext{
${ }^{46}$ Insurance regulators require substantial documentation of expected medical spending to ensure the solvency of insurers. These projections ordinarily reflect provider rates and expected utilization.
} 
hospitals and the insurer better off. The harm to customers will differ across markets, with those facing lower premiums as a result of lower negotiated prices benefiting from the merger.

Though this stand-alone common insurer effect may be relevant in some cases, we conjecture that it is less empirically relevant than the common customer effect (which presumes a common insurer). First, for this particular effect to obtain, hospitals must be paid linear fees rather than twopart tariffs. Second, premium-setting must lag behind price negotiations sufficiently for premiums to be set in response to prices. Either assumption may fail in particular markets. Finally, the double marginalization effect may result in a weighted average decrease in hospital prices; empirically, we observe an increase. 
Table 1: Hospital Mergers Investigated by the FTC

\begin{tabular}{|c|c|c|c|c|c|c|c|c|}
\hline & Acquirer & Target & $\begin{array}{l}\text { Area with potential } \\
\text { horizontal concern }\end{array}$ & $\begin{array}{l}\text { Year of } \\
\text { Merger }\end{array}$ & In Sample? & $\begin{array}{c}\text { Reason excluded from } \\
\text { sample }\end{array}$ & $\begin{array}{c}\text { Number of hospitals } \\
\text { obtaining adjacent } \\
\text { system member }\end{array}$ & $\begin{array}{c}\text { Number of hospitals } \\
\text { obtaining non-adjacent } \\
\text { system member } \\
\end{array}$ \\
\hline 1 & Tenet Healthcare & OrNda Healthcorp & San Luis Obispo, CA & 1997 & Yes & \multirow{10}{*}{ N/A } & 72 & 23 \\
\hline 2 & Inova Health Systrem & Alexandria Health Services & Alexandria, VA & 1997 & Yes & & 2 & 0 \\
\hline 3 & Tenet Healthcare & Doctors Regional Medical Center & Poplar Bluff, MO & 1999 & Yes & & 5 & 0 \\
\hline 4 & Sutter Health & Summit Medical Center & $\begin{array}{c}\text { Oakland/Berkeley, } \\
\text { CA }\end{array}$ & 2000 & Yes & & 19 & 0 \\
\hline 5 & Piedmont Healthcare & Newnan Hospital & Atlanta, GA & 2007 & Yes & & 2 & 0 \\
\hline 6 & $\begin{array}{l}\text { University of Pittsburgh Medical } \\
\text { Center }\end{array}$ & Mercy Hospital of Pittsburgh & Pittsburgh, PA & 2008 & Yes & & 6 & 0 \\
\hline 7 & Banner Health & Sun Health & Sun City, AZ & 2008 & Yes & & 5 & 5 \\
\hline 8 & St. Elizabeth Medical Center & St. Luke Hospital & $\begin{array}{c}\text { Northern Kentucky, } \\
\text { KY }\end{array}$ & 2008 & Yes & & 1 & 0 \\
\hline 9 & Hartford Healthcare & $\begin{array}{l}\text { Central Connecticut Health } \\
\text { Alliance }\end{array}$ & Hartford, CT & 2011 & Yes & & 2 & 0 \\
\hline 10 & St. Peters Healthcare Services & $\begin{array}{l}\text { Northeast Health and Seton } \\
\text { Health }\end{array}$ & Albany/Troy, NY & 2011 & Yes & & 2 & 0 \\
\hline 11 & Columbus Hospital & $\begin{array}{l}\text { Montana Deaconess Medical } \\
\text { Center }\end{array}$ & Great Falls, MT & 1996 & No & No pre period & & \\
\hline 12 & Miami Valley Hospital & Good Samaritan Hospital & Dayton, $\mathrm{OH}$ & 1996 & No & One acquiring one & & \\
\hline 13 & Butterworth Health Corporation & $\begin{array}{l}\text { Blodgett Memorial Medical } \\
\text { Center }\end{array}$ & Grand Rapids, MI & 1997 & No & One acquiring one & & \\
\hline 14 & Buffalo General Health System & Millard Fillmore Health System & Buffalo, NY & 1998 & No & One acquiring one & & \\
\hline 15 & $\begin{array}{l}\text { New Hanover Regional Medical } \\
\text { Center }\end{array}$ & $\begin{array}{l}\text { Columbia Cape Fear Memorial } \\
\text { Hospital }\end{array}$ & Wilmington, $\mathrm{NC}$ & 1998 & No & One acquiring one & & \\
\hline 16 & $\begin{array}{l}\text { Evanston Northwestern } \\
\text { Healthcare }\end{array}$ & Highland Park Hospital & Evanston, IL & 2000 & No & One acquiring one* & & \\
\hline 17 & Victory Memorial Hospital & St. Therese Hospital & Waukegan, IL & 2002 & No & One acquiring one & & \\
\hline 18 & Scott \& White Healthcare & King's Daughters Hospital & Temple, TX & 2009 & No & $\begin{array}{l}\text { Converted into a } \\
\text { children's hospital }\end{array}$ & & \\
\hline 19 & ProMedica Health System & St. Luke's Hospital & Toledo, $\mathrm{OH}$ & 2010 & No & $\begin{array}{l}\text { Litigated beyond time } \\
\text { period of the data }\end{array}$ & & \\
\hline 20 & Phoebe Putney Health System & Palmyra Park Hospital & Albany, GA & 2011 & No & $\begin{array}{l}\text { Litigated beyond time } \\
\text { period of the data }\end{array}$ & & \\
\hline 21 & Inova Health System & Prince William Hospital & $\begin{array}{c}\text { Northern Virginia, } \\
\text { VA }\end{array}$ & $\mathrm{X}$ & No & Transaction abandoned & & \\
\hline 22 & Lifespan & Care New England & RI & $\mathrm{x}$ & No & Transaction abandoned & & \\
\hline 23 & OSF Healthcare System & Rockford Health System & Rockford, IL & $\mathrm{x}$ & No & Transaction abandoned & & \\
\hline
\end{tabular}

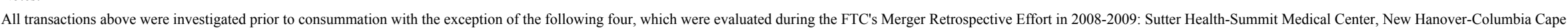
Fear, Victory Memorial-St. Therese, Evanston Northwestern-Highland Park.

*Evanston Northwestern owned two hospitals (Evanston Hospital and Glenbrook Hospital) prior to the acquisition of Highland Park, but they report consolidated data using a single Medicare provider number 
Table 2: Hospital Merger Transaction Statistics in Broad Sample, 2002-2012

\begin{tabular}{|c|c|c|c|c|c|}
\hline \multirow[b]{2}{*}{ Transaction Filter } & \multirow{2}{*}{$\begin{array}{c}\text { Number of } \\
\text { Transactions }\end{array}$} & \multicolumn{2}{|c|}{ Acquirer Size (\# of hospitals) } & \multicolumn{2}{|c|}{ Target Size (\# of hospitals) } \\
\hline & & Median & Mean & Median & Mean \\
\hline All Transactions (from Irving Levin*) & 426 & 9.0 & 24.0 & 1.0 & 1.6 \\
\hline Generates $1+$ adjacent treatment hospitals & 270 & 23.0 & 33.8 & 1.0 & 1.8 \\
\hline Generates $1+$ non-adjacent treatment hospitals & 240 & 29.0 & 39.4 & 1.0 & 2.0 \\
\hline \multicolumn{6}{|l|}{ Clean in the 2 years before and after treatment and: } \\
\hline Generates $1+$ adjacent treatment hospitals & 43 & 5.0 & 8.8 & 1.0 & 1.3 \\
\hline Generates $1+$ non-adjacent treatment hospitals & 22 & 8.5 & 15.9 & 1.0 & 1.6 \\
\hline
\end{tabular}

$$
\text { Notes: }
$$

"Clean in the 2 years before and after treatment" means that the hospital is unaffected (either directly or by being within 30 minutes' drive of an affected hospital) by other mergers during this period

We consider only transactions involving "consolidation", which is defined as an existing hospital or system gaining members (as opposed to, say, a transfer of assets). This definition captures 85 percent of the deals in the Irving Levin Hospital Acquisition Reports. 
Table 3: Descriptive Statistics

\begin{tabular}{|c|c|c|c|c|}
\hline \multicolumn{5}{|c|}{ Panel A: FTC Sample } \\
\hline & $\begin{array}{c}\text { Adjacent } \\
\text { Treatments }\end{array}$ & $\begin{array}{c}\text { Non-Adjacent } \\
\text { Treatments } \\
\end{array}$ & Control Group 1 & Control Group 2 \\
\hline \# of Hospitals & 116 & 28 & 4,706 & 2,692 \\
\hline (acquiring/target) & $88 / 28$ & $21 / 7$ & N/A & N/A \\
\hline CMI & 1.43 & 1.36 & 1.28 & 1.35 \\
\hline Beds & 207 & 157 & 151 & 181 \\
\hline$\%$ Medicaid & $15.8 \%$ & $16.9 \%$ & $14.0 \%$ & $13.6 \%$ \\
\hline For-Profit & $64.2 \%$ & $80.4 \%$ & $17.3 \%$ & $25.3 \%$ \\
\hline Urban & $88.8 \%$ & $71.4 \%$ & $58.4 \%$ & $69.2 \%$ \\
\hline \multicolumn{5}{|l|}{ Census Region } \\
\hline Midwest & $6.0 \%$ & $0.0 \%$ & $30.5 \%$ & $28.8 \%$ \\
\hline Northeast & $8.6 \%$ & $3.6 \%$ & $13.8 \%$ & $13.0 \%$ \\
\hline South & $37.1 \%$ & $57.1 \%$ & $38.7 \%$ & $42.4 \%$ \\
\hline West & $48.3 \%$ & $39.3 \%$ & $17.0 \%$ & $15.8 \%$ \\
\hline \multicolumn{5}{|c|}{ Notes: The unit of observation is the hospital-year unless otherwise noted } \\
\hline \multicolumn{5}{|c|}{ Panel B: Broad Sample } \\
\hline & $\begin{array}{c}\text { Adjacent } \\
\text { Treatments }\end{array}$ & $\begin{array}{c}\text { Non-Adjacent } \\
\text { Treatments } \\
\end{array}$ & Control Group 1 & Control Group 2 \\
\hline \# of Hospitals & 104 & 55 & 4,755 & 756 \\
\hline \# of Hospitals (full data) & 81 & 38 & 4,055 & 592 \\
\hline (acquiring/target) & $76 / 5$ & $37 / 1$ & N/A & $\mathrm{N} / \mathrm{A}$ \\
\hline CMI & 1.31 & 1.26 & 1.29 & 1.32 \\
\hline Beds & 147 & 148 & 153 & 174 \\
\hline$\%$ Medicaid & $12.5 \%$ & $12.5 \%$ & $14.4 \%$ & $13.1 \%$ \\
\hline For-Profit & $6.1 \%$ & $6.6 \%$ & $21.7 \%$ & $6.3 \%$ \\
\hline Urban & $49.4 \%$ & $44.7 \%$ & $60.3 \%$ & $65.2 \%$ \\
\hline \multicolumn{5}{|l|}{ Census Region } \\
\hline Midwest & $42.0 \%$ & $63.2 \%$ & $26.9 \%$ & $32.3 \%$ \\
\hline Northeast & $4.9 \%$ & $2.6 \%$ & $15.0 \%$ & $23.1 \%$ \\
\hline South & $40.7 \%$ & $21.1 \%$ & $39.0 \%$ & $31.6 \%$ \\
\hline West & $12.3 \%$ & $13.2 \%$ & $19.1 \%$ & $13.0 \%$ \\
\hline
\end{tabular}

Notes: The unit of observation is the hospital-year unless otherwise noted 
Table 4: Pre-Post Regression Results, FTC Sample

\begin{tabular}{|c|c|c|}
\hline & \multicolumn{2}{|c|}{ Dependent variable is $\ln$ (price) } \\
\hline & $(1)$ & $(2)$ \\
\hline & Control Group 1 & Control Group 2 \\
\hline \multirow[t]{2}{*}{ Adj Treated* $(\mathrm{t}=0)$} & 0.012 & 0.010 \\
\hline & $(0.016)$ & $(0.016)$ \\
\hline \multirow[t]{2}{*}{ Adj Treated* $(t>0)$} & $0.068 * * *$ & $0.064 * * *$ \\
\hline & $(0.023)$ & $(0.023)$ \\
\hline \multirow{2}{*}{ Non-Adj Treated* $(t=0)$} & -0.049 & -0.048 \\
\hline & $(0.058)$ & $(0.058)$ \\
\hline \multirow[t]{2}{*}{ Non-Adj Treated $*(t>0)$} & -0.014 & -0.013 \\
\hline & $(0.054)$ & $(0.054)$ \\
\hline \multirow[t]{2}{*}{$\ln (\mathrm{CMI})$} & $0.291 * * *$ & $0.286 * * *$ \\
\hline & $(0.047)$ & $(0.062)$ \\
\hline \multirow[t]{2}{*}{$\ln$ (Total Beds) } & $0.091 * * *$ & $0.107 * * *$ \\
\hline & $(0.016)$ & $(0.020)$ \\
\hline \multirow[t]{2}{*}{$\%$ Medicaid } & 0.055 & 0.070 \\
\hline & $(0.040)$ & $(0.052)$ \\
\hline \multirow[t]{2}{*}{ For-Profit } & $0.048 * * *$ & $0.054 * * *$ \\
\hline & $(0.017)$ & $(0.020)$ \\
\hline Observations & 59,666 & 33,896 \\
\hline Number of hospitals & 4,850 & 2,836 \\
\hline R-squared (within) & 0.554 & 0.570 \\
\hline $\mathrm{p}$-value for $\mathrm{H}_{0}$ : coefficients for & & \\
\hline Adj* $(t>0)$ and Non-Adj* & 0.158 & 0.187 \\
\hline$(t>0)$ are same & & \\
\hline
\end{tabular}

Notes: Standard errors clustered by hospital, ${ }^{* *} \mathrm{p}<0.01,{ }^{* *} \mathrm{p}<0.05,{ }^{*} \mathrm{p}<0.10$ 
Table 5: Pre-Post Regression Results, Broad Sample

\begin{tabular}{|c|c|c|c|}
\hline & \multicolumn{3}{|c|}{ Dependent variable is $\ln ($ price $)$} \\
\hline & (1) & (2) & (3) \\
\hline & Control Group 1 & Control Group 2 & $\begin{array}{c}\text { Control Group } 2 \\
\text { No Targets } \\
\end{array}$ \\
\hline \multirow[t]{2}{*}{ Adj Treated $*(t=0)$} & 0.032 & 0.035 & 0.040 \\
\hline & $(0.030)$ & $(0.029)$ & $(0.030)$ \\
\hline \multirow[t]{2}{*}{ Adj Treated* $(t>0)$} & $0.102 * *$ & $0.093 * *$ & $0.101 * *$ \\
\hline & $(0.046)$ & $(0.046)$ & $(0.047)$ \\
\hline \multirow[t]{2}{*}{ Non-Adj Treated $*(t=0)$} & -0.017 & -0.019 & -0.019 \\
\hline & $(0.025)$ & $(0.027)$ & $(0.027)$ \\
\hline \multirow[t]{2}{*}{ Non-Adj Treated $*(t>0)$} & -0.031 & -0.032 & -0.028 \\
\hline & $(0.030)$ & $(0.034)$ & $(0.034)$ \\
\hline \multirow[t]{2}{*}{$\ln (\mathrm{CMI})$} & $0.258 * * *$ & 0.213 & 0.213 \\
\hline & $(0.056)$ & $(0.160)$ & $(0.161)$ \\
\hline \multirow[t]{2}{*}{$\ln ($ Total Beds $)$} & $0.092 * * *$ & $0.117^{*}$ & $0.115^{*}$ \\
\hline & $(0.018)$ & $(0.067)$ & $(0.067)$ \\
\hline \multirow[t]{2}{*}{$\%$ Medicaid } & $0.103 * *$ & 0.164 & 0.166 \\
\hline & $(0.051)$ & $(0.149)$ & $(0.150)$ \\
\hline \multirow[t]{2}{*}{ For-Profit } & $0.040 * *$ & 0.072 & 0.069 \\
\hline & $(0.019)$ & $(0.049)$ & $(0.049)$ \\
\hline Observations & 40,994 & 4,422 & 4,392 \\
\hline Number of hospitals & 4,174 & 711 & 705 \\
\hline R-squared (within) & 0.462 & 0.435 & 0.436 \\
\hline \multicolumn{4}{|l|}{$\mathrm{p}$-value for $\mathrm{H}_{0}$ : coefficients for } \\
\hline $\begin{array}{l}\text { Adj* }(t>0) \text { and Non-Adj* } \\
(t>0) \text { are same }\end{array}$ & 0.017 & 0.021 & 0.019 \\
\hline
\end{tabular}

Notes: Standard errors clustered by hospital, ${ }^{* * *} \mathrm{p}<0.01,{ }^{* *} \mathrm{p}<0.05,{ }^{*} \mathrm{p}<0.10$ 
Table 6: Evaluating Alternative Explanations in Broad Sample

\begin{tabular}{|c|c|c|c|c|}
\hline & \multicolumn{4}{|c|}{ Dependent variable is $\ln$ (price) } \\
\hline & $\begin{array}{c}(1) \\
\text { Control Group } 2 \\
\text { No Targets } \\
\end{array}$ & $\begin{array}{c}(2) \\
\text { Control Group } 2 \\
\text { No Targets } \\
\end{array}$ & $\begin{array}{c}(3) \\
\text { Control Group } 2 \\
\text { No Targets } \\
\end{array}$ & $\begin{array}{c}(4) \\
\text { Control Group } 2 \\
\text { No Targets } \\
\end{array}$ \\
\hline Adj Treated $*(t=0)$ & $\begin{array}{c}0.040 \\
(0.030)\end{array}$ & $\begin{array}{c}0.038 \\
(0.030)\end{array}$ & $\begin{array}{c}0.037 \\
(0.031)\end{array}$ & $\begin{array}{c}0.033 \\
(0.032)\end{array}$ \\
\hline Adj Treated $*(t>0)$ & $\begin{array}{c}0.101^{* *} \\
(0.047)\end{array}$ & $\begin{array}{c}0.167 * * * \\
(0.063)\end{array}$ & $\begin{array}{c}0.141 * * * \\
(0.048)\end{array}$ & $\begin{array}{l}0.065^{*} \\
(0.035)\end{array}$ \\
\hline Adj Treated*(t>0)*Acquirer above median share beds & & $\begin{array}{l}-0.092 \\
(0.084)\end{array}$ & & $\begin{array}{l}0.114 \\
(-.071)\end{array}$ \\
\hline Adj Treated*(t>0)*Target above median share beds & & & $\begin{array}{l}-0.085 \\
(0.081)\end{array}$ & $\begin{array}{l}0.242 * * \\
(0.106)\end{array}$ \\
\hline $\begin{array}{c}\text { Adj Treated* }(t>0) * \text { Acquirer above median share } \\
\text { beds*Target above median share beds }\end{array}$ & & & & $\begin{array}{c}-0.444 * * * \\
(0.138)\end{array}$ \\
\hline Non-Adj Treated* $(\mathrm{t}=0)$ & $\begin{array}{l}-0.019 \\
(0.027)\end{array}$ & $\begin{array}{l}-0.020 \\
(0.027)\end{array}$ & $\begin{array}{l}-0.018 \\
(0.027)\end{array}$ & $\begin{array}{l}-0.018 \\
(0.027)\end{array}$ \\
\hline Non-Adj Treated $*(t>0)$ & $\begin{array}{l}-0.028 \\
(0.034)\end{array}$ & $\begin{array}{l}-0.029 \\
(0.034)\end{array}$ & $\begin{array}{l}-0.027 \\
(0.034)\end{array}$ & $\begin{array}{l}-0.026 \\
(0.034)\end{array}$ \\
\hline $\ln (\mathrm{CMI})$ & $\begin{array}{c}0.213 \\
(0.161)\end{array}$ & $\begin{array}{l}0.216 \\
(0.161)\end{array}$ & $\begin{array}{c}0.211 \\
(0.160)\end{array}$ & $\begin{array}{c}0.229 \\
(0.160)\end{array}$ \\
\hline $\ln$ (Total Beds) & $\begin{array}{l}0.115^{*} \\
(0.067)\end{array}$ & $\begin{array}{l}0.114^{*} \\
(0.067)\end{array}$ & $\begin{array}{l}0.113^{*} \\
(0.067)\end{array}$ & $\begin{array}{l}0.112^{*} \\
(0.067)\end{array}$ \\
\hline$\%$ Medicaid & $\begin{array}{c}0.166 \\
(0.150)\end{array}$ & $\begin{array}{c}0.169 \\
(0.149)\end{array}$ & $\begin{array}{c}0.164 \\
(0.148)\end{array}$ & $\begin{array}{c}0.152 \\
(0.147)\end{array}$ \\
\hline For-Profit & $\begin{array}{c}0.069 \\
(0.049)\end{array}$ & $\begin{array}{c}0.071 \\
(0.050)\end{array}$ & $\begin{array}{c}0.066 \\
(0.046)\end{array}$ & $\begin{array}{c}0.063 \\
(0.044)\end{array}$ \\
\hline Observations & 4,392 & 4,392 & 4,392 & 4,392 \\
\hline Number of hospitals & 705 & 705 & 705 & 705 \\
\hline R-squared (within) & 0.436 & 0.437 & 0.437 & 0.443 \\
\hline
\end{tabular}

Notes: Standard errors clustered by hospital, ${ }^{* * *} \mathrm{p}<0.01,{ }^{* *} \mathrm{p}<0.05,{ }^{*} \mathrm{p}<0.10$.

Estimated price effect

among Adj

Treated $*(t>0)$

Acquirer below median share beds \& Target below median share beds

$0.065^{*}$

(0.035)

Acquirer above median share beds \& Target below median share beds

$0.179 * * *$

(0.062)

Acquirer below median share beds \& Target above median share beds

$0.306^{* * *}$

$(0.103)$

Acquirer above median share beds \& Target above median share beds

$-0.023$

$(0.753)$ 
Figure 1. Defining Treatment Groups, FTC Sample

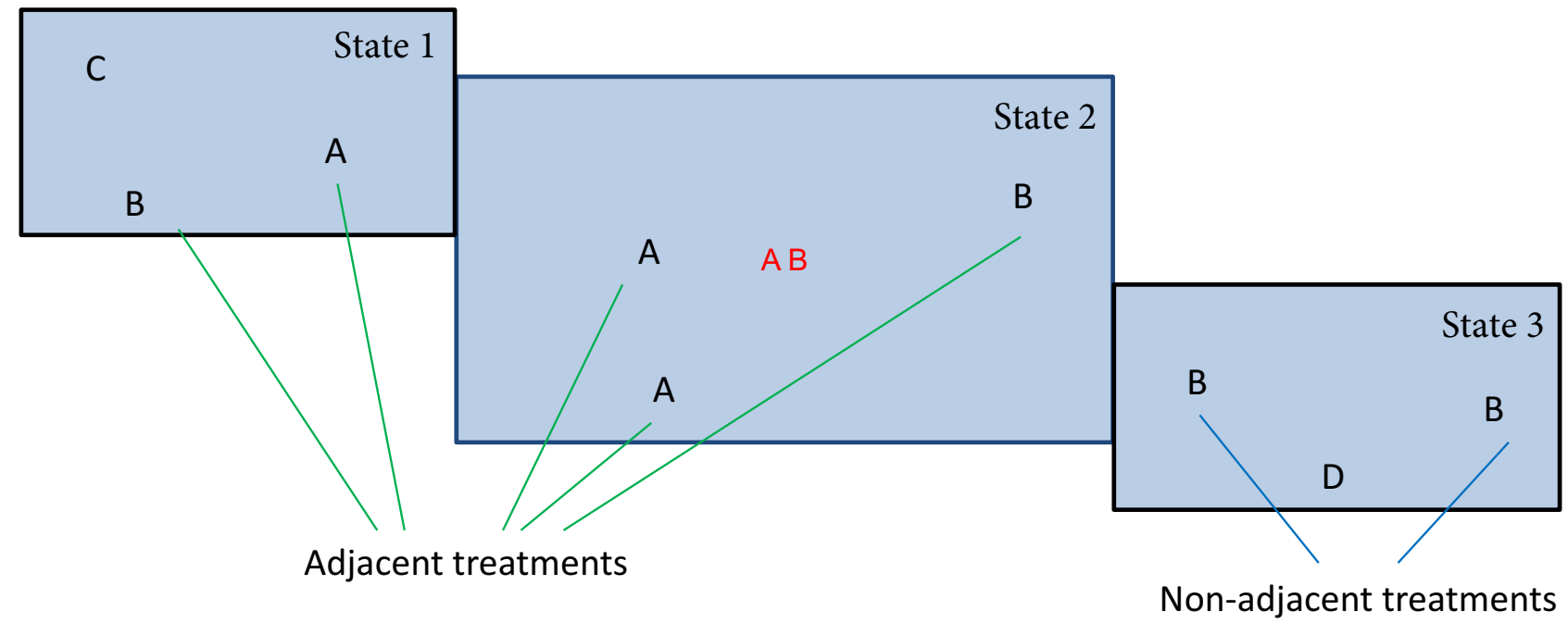

Notes: Figure depicts a merger between system A and system B; hospitals C and D belong to other systems. Hospitals in red generate the FTC investigation and are excluded from estimation. 
Figure 2. Defining Treatment Groups, Broad Sample

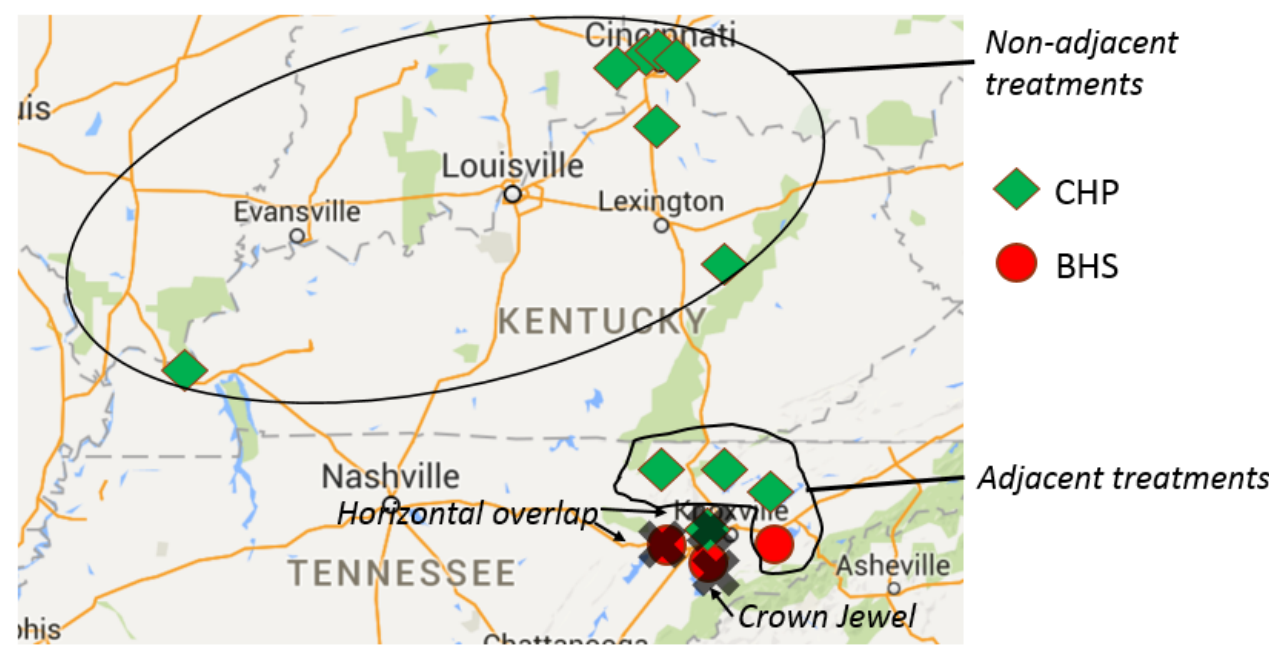

Notes: Figure depicts the 2007 merger between Catholic Healthcare Partners (CHP) and Baptist Health System (BHS). The largest BHS hospital (noted "Crown Jewel") is dropped from the estimation sample, as are all hospitals from opposing systems located within 30 minutes' drive of one another. 

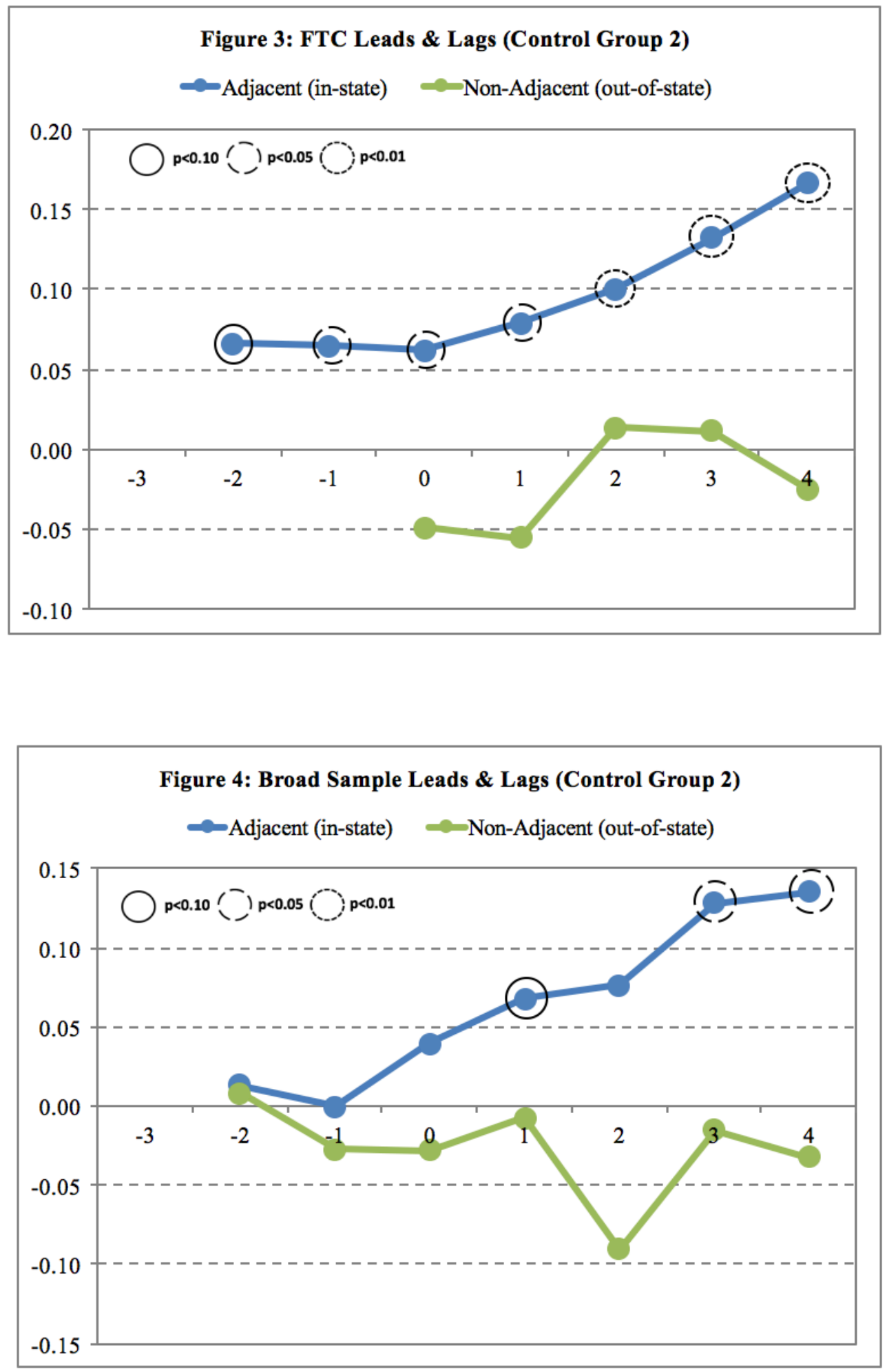


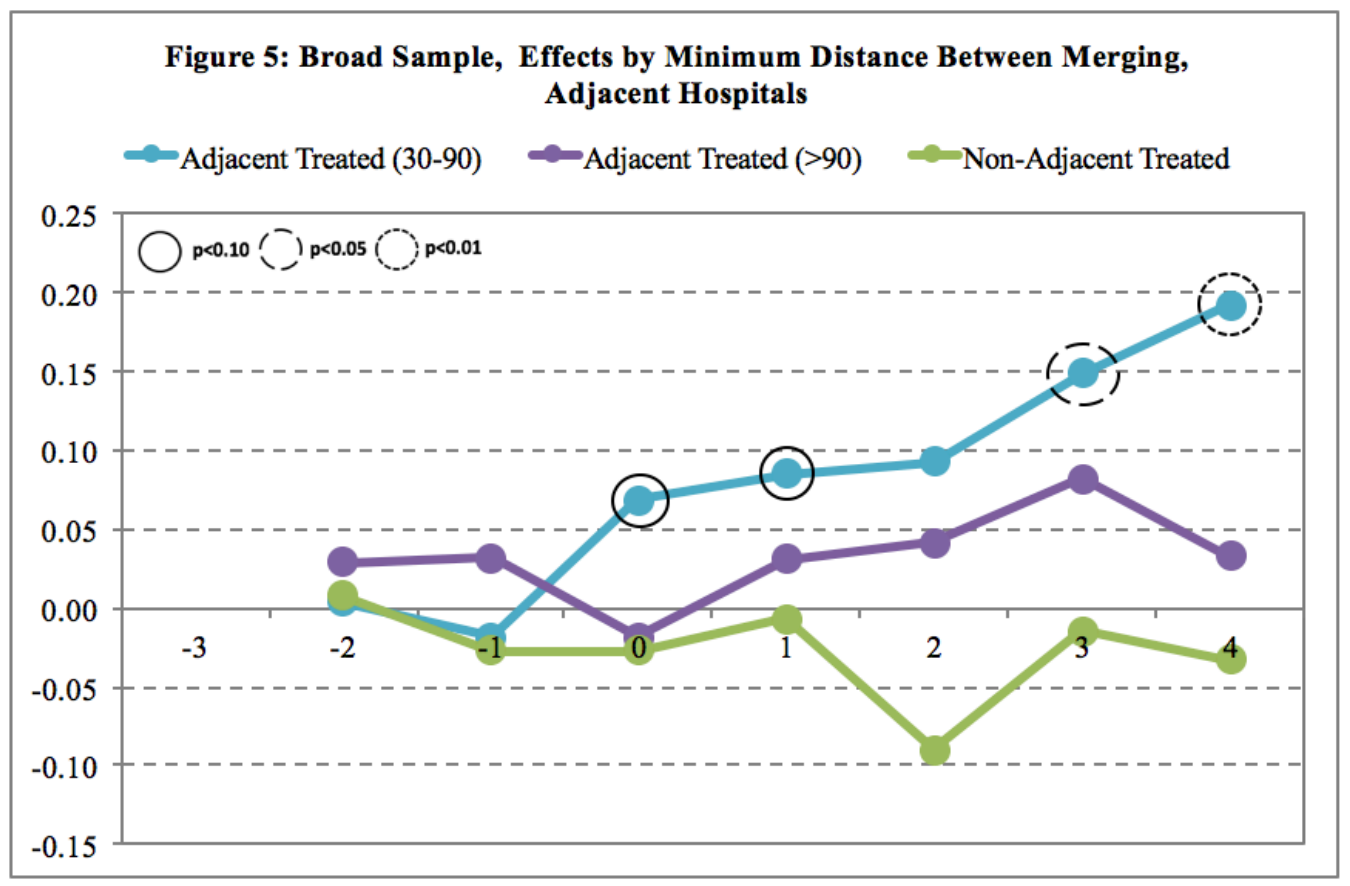


Appendix Table 1:

Leads \& Lags Regression Results, FTC Sample

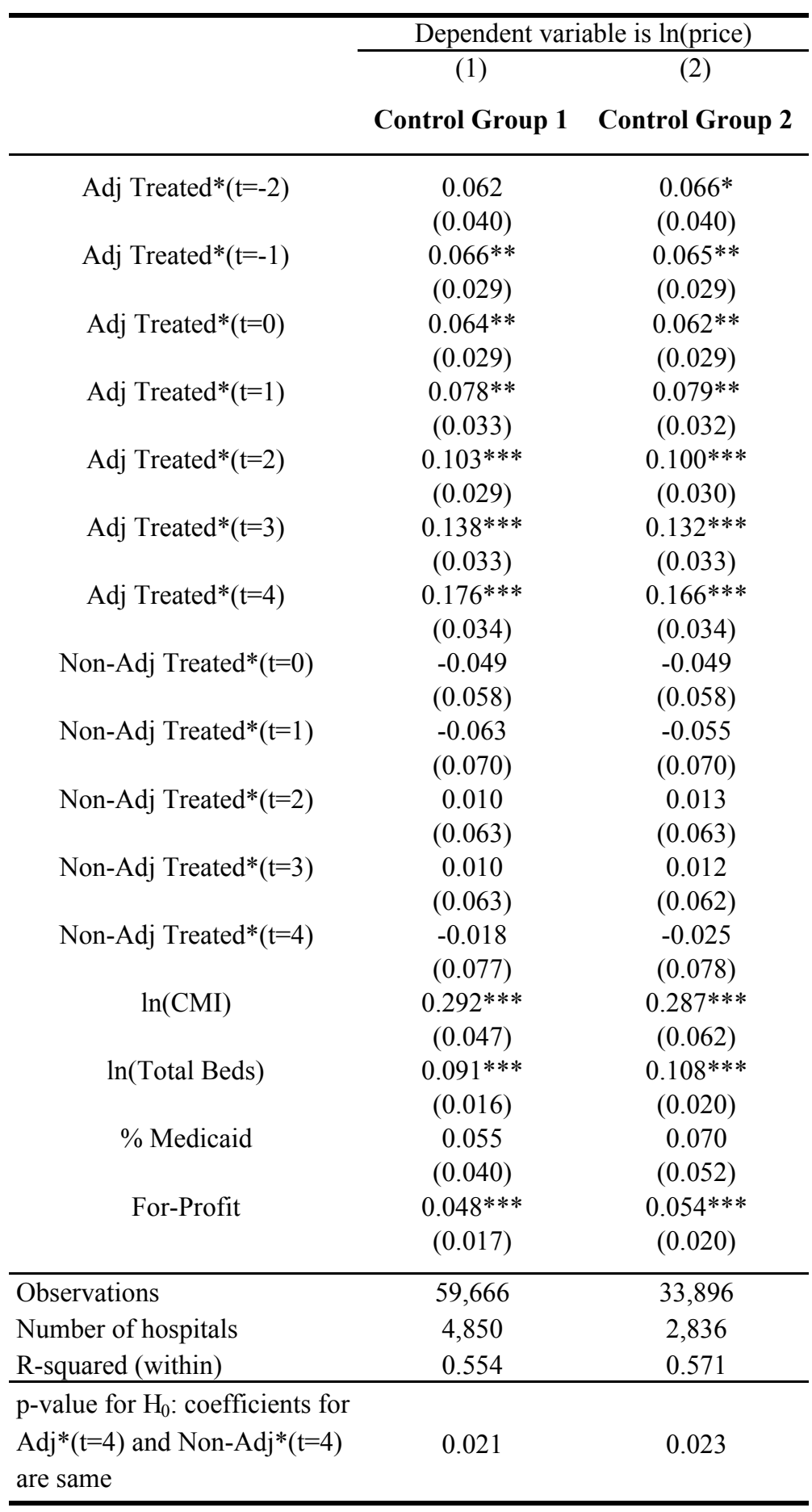

Notes: Standard errors clustered by hospital, ${ }^{* * *} \mathrm{p}<0.01,{ }^{* *} \mathrm{p}<0.05,{ }^{*} \mathrm{p}<0.1$ 
Appendix Table 2:

Leads \& Lags Regression Results, Broad Sample

\begin{tabular}{|c|c|c|c|}
\hline & \multicolumn{3}{|c|}{ Dependent variable is $\ln$ (price) } \\
\hline & (1) & (2) & (3) \\
\hline & Control Group 1 & Control Group 2 & $\begin{array}{c}\text { Control Group 2, } \\
\text { No Targets } \\
\end{array}$ \\
\hline \multirow[t]{2}{*}{ Adj Treated* $(\mathrm{t}=-2)$} & 0.016 & 0.013 & 0.018 \\
\hline & $(0.027)$ & $(0.027)$ & $(0.029)$ \\
\hline \multirow[t]{2}{*}{ Adj Treated* $(\mathrm{t}=-1)$} & 0.009 & -0.001 & 0.009 \\
\hline & $(0.035)$ & $(0.035)$ & $(0.036)$ \\
\hline \multirow[t]{2}{*}{ Adj Treated $*(t=0)$} & 0.040 & 0.039 & 0.049 \\
\hline & $(0.034)$ & $(0.034)$ & $(0.035)$ \\
\hline \multirow[t]{2}{*}{ Adj Treated $*(t=1)$} & $0.075^{*}$ & $0.068 *$ & $0.076^{*}$ \\
\hline & $(0.040)$ & $(0.041)$ & $(0.042)$ \\
\hline \multirow{2}{*}{ Adj Treated* $(\mathrm{t}=2)$} & $0.094 *$ & 0.076 & 0.089 \\
\hline & $(0.053)$ & $(0.054)$ & $(0.055)$ \\
\hline \multirow[t]{2}{*}{ Adj Treated* $(\mathrm{t}=3)$} & $0.144 * * *$ & $0.128 * *$ & $0.148 * * *$ \\
\hline & $(0.053)$ & $(0.052)$ & $(0.053)$ \\
\hline \multirow[t]{2}{*}{ Adj Treated* $(\mathrm{t}=4)$} & $0.144 * *$ & $0.135^{* *}$ & $0.143^{* *}$ \\
\hline & $(0.058)$ & $(0.058)$ & $(0.058)$ \\
\hline \multirow[t]{2}{*}{ Non-Adj Treated*(t=-2) } & 0.009 & 0.008 & 0.006 \\
\hline & $(0.073)$ & $(0.075)$ & $(0.075)$ \\
\hline \multirow[t]{2}{*}{ Non-Adj Treated*(t=-1) } & -0.019 & -0.028 & -0.030 \\
\hline & $(0.065)$ & $(0.067)$ & $(0.067)$ \\
\hline \multirow[t]{2}{*}{ Non-Adj Treated $*(t=0)$} & -0.022 & -0.028 & -0.031 \\
\hline & $(0.068)$ & $(0.071)$ & $(0.071)$ \\
\hline \multirow[t]{2}{*}{ Non-Adj Treated $*(t=1)$} & 0.000 & -0.007 & -0.005 \\
\hline & $(0.075)$ & $(0.078)$ & $(0.078)$ \\
\hline \multirow[t]{2}{*}{ Non-Adj Treated* $(\mathrm{t}=2)$} & -0.084 & -0.091 & -0.089 \\
\hline & $(0.079)$ & $(0.083)$ & $(0.083)$ \\
\hline \multirow[t]{2}{*}{ Non-Adj Treated* $(\mathrm{t}=3)$} & -0.000 & -0.015 & -0.011 \\
\hline & $(0.089)$ & $(0.094)$ & $(0.095)$ \\
\hline \multirow[t]{2}{*}{ Non-Adj Treated* $(t=4)$} & -0.033 & -0.032 & -0.032 \\
\hline & $(0.089)$ & $(0.094)$ & $(0.094)$ \\
\hline \multirow[t]{2}{*}{$\ln (\mathrm{CMI})$} & $0.258 * * *$ & 0.214 & 0.214 \\
\hline & $(0.056)$ & $(0.161)$ & $(0.161)$ \\
\hline \multirow[t]{2}{*}{$\ln ($ Total Beds) } & $0.092 * * *$ & $0.116^{*}$ & $0.114 *$ \\
\hline & $(0.018)$ & $(0.067)$ & $(0.068)$ \\
\hline \multirow[t]{2}{*}{$\%$ Medicaid } & $0.102 * *$ & 0.162 & 0.166 \\
\hline & $(0.051)$ & $(0.149)$ & $(0.150)$ \\
\hline \multirow[t]{2}{*}{ For-Profit } & $0.040 * *$ & 0.067 & 0.064 \\
\hline & $(0.019)$ & $(0.046)$ & $(0.045)$ \\
\hline Observations & 40,994 & 4,422 & 4,392 \\
\hline Number of hospitals & 4,174 & 711 & 705 \\
\hline R-squared (within) & 0.462 & 0.436 & 0.438 \\
\hline $\mathrm{p}$-value for $\mathrm{H}_{0}$ : coefficients for & & & \\
\hline $\begin{array}{l}\operatorname{Adj} *(t=4) \text { and Non-Adj*(t=4) } \\
\text { are same }\end{array}$ & 0.096 & 0.119 & 0.103 \\
\hline
\end{tabular}

Notes: Standard errors clustered by hospital, ${ }^{* * *} \mathrm{p}<0.01,{ }^{* *} \mathrm{p}<0.05,{ }^{*} \mathrm{p}<0.1$ 
Appendix Table 3:

FTC Pre-Post Regression Results, Dropping One Transaction at a Time (Control Group 2)

\begin{tabular}{|c|c|c|c|c|c|c|c|c|c|c|c|}
\hline & \multirow[b]{2}{*}{ All } & \multicolumn{10}{|c|}{ Excluding: } \\
\hline & & Tenet / OrNda & $\begin{array}{c}\text { Inova / } \\
\text { Alexandria }\end{array}$ & $\begin{array}{c}\text { Tenet / Doctors } \\
\text { Regional } \\
\end{array}$ & Sutter / Summit & $\begin{array}{c}\text { Piedmont / } \\
\text { Newnan }\end{array}$ & UPMC / Mercy & Banner / Sun & $\begin{array}{c}\text { St. Elizabeth / } \\
\text { St. Luke }\end{array}$ & $\begin{array}{c}\text { Hartford / } \\
\text { Central } \\
\text { Connecticut }\end{array}$ & $\begin{array}{c}\text { St. Peters / } \\
\text { Northeast / } \\
\text { Seton } \\
\end{array}$ \\
\hline Adj Treated $*(t=0)$ & $\begin{array}{c}0.010 \\
(0.016)\end{array}$ & $\begin{array}{c}0.023 \\
(0.019)\end{array}$ & $\begin{array}{c}0.010 \\
(0.017)\end{array}$ & $\begin{array}{c}0.009 \\
(0.017)\end{array}$ & $\begin{array}{c}0.010 \\
(0.019)\end{array}$ & $\begin{array}{l}0.009 \\
(0.017)\end{array}$ & $\begin{array}{l}0.005 \\
(0.017)\end{array}$ & $\begin{array}{l}0.020 \\
(0.016)\end{array}$ & $\begin{array}{c}0.009 \\
(0.017)\end{array}$ & $\begin{array}{l}0.002 \\
(0.016)\end{array}$ & $\begin{array}{l}0.010 \\
(0.017)\end{array}$ \\
\hline Adj Treated* $(t>0)$ & $\begin{array}{c}0.064 * * * \\
(0.023)\end{array}$ & $\begin{array}{l}0.056^{*} \\
(0.032)\end{array}$ & $\begin{array}{c}0.065^{* * * *} \\
(0.024)\end{array}$ & $\begin{array}{c}0.064 * * * \\
(0.024)\end{array}$ & $\begin{array}{r}0.056^{* *} \\
(0.022)\end{array}$ & $\begin{array}{c}0.064 * * * \\
(0.024)\end{array}$ & $\begin{array}{r}0.063^{* *} \\
(0.025)\end{array}$ & $\begin{array}{c}0.081 * * * \\
(0.022)\end{array}$ & $\begin{array}{c}0.062 * * * \\
(0.023)\end{array}$ & $\begin{array}{r}0.061^{* *} \\
(0.024)\end{array}$ & $\begin{array}{c}0.066^{* * *} \\
(0.023)\end{array}$ \\
\hline Non-Adj Treated $(t=0)$ & $\begin{array}{l}-0.048 \\
(0.058)\end{array}$ & $\begin{array}{c}0.046 \\
(0.031)\end{array}$ & $\begin{array}{l}-0.048 \\
(0.058)\end{array}$ & $\begin{array}{l}-0.048 \\
(0.058)\end{array}$ & $\begin{array}{l}-0.049 \\
(0.058)\end{array}$ & $\begin{array}{l}-0.048 \\
(0.058)\end{array}$ & $\begin{array}{l}-0.048 \\
(0.058)\end{array}$ & $\begin{array}{l}-0.068 \\
(0.071)\end{array}$ & $\begin{array}{l}-0.048 \\
(0.058)\end{array}$ & $\begin{array}{l}-0.048 \\
(0.058)\end{array}$ & $\begin{array}{l}-0.048 \\
(0.058)\end{array}$ \\
\hline Non-Adj Treated* $(t>0)$ & $\begin{array}{l}-0.013 \\
(0.054)\end{array}$ & $\begin{array}{c}0.004 \\
(0.053)\end{array}$ & $\begin{array}{l}-0.013 \\
(0.054)\end{array}$ & $\begin{array}{l}-0.013 \\
(0.054)\end{array}$ & $\begin{array}{l}-0.013 \\
(0.054)\end{array}$ & $\begin{array}{l}-0.013 \\
(0.054)\end{array}$ & $\begin{array}{l}-0.013 \\
(0.054)\end{array}$ & $\begin{array}{l}-0.015 \\
(0.064)\end{array}$ & $\begin{array}{l}-0.013 \\
(0.054)\end{array}$ & $\begin{array}{l}-0.013 \\
(0.054)\end{array}$ & $\begin{array}{l}-0.013 \\
(0.054)\end{array}$ \\
\hline $\ln (\mathrm{CMI})$ & $\begin{array}{c}0.286^{* * *} \\
(0.062)\end{array}$ & $\begin{array}{c}0.288^{* * * *} \\
(0.063)\end{array}$ & $\begin{array}{c}0.286 * * * \\
(0.062)\end{array}$ & $\begin{array}{c}0.286 * * * \\
(0.062)\end{array}$ & $\begin{array}{c}0.289^{* * * *} \\
(0.062)\end{array}$ & $\begin{array}{c}0.286^{* * *} \\
(0.062)\end{array}$ & $\begin{array}{c}0.287 * * * \\
(0.062)\end{array}$ & $\begin{array}{c}0.287 * * * \\
(0.062)\end{array}$ & $\begin{array}{c}0.286^{* * * *} \\
(0.062)\end{array}$ & $\begin{array}{c}0.287 * * * \\
(0.062)\end{array}$ & $\begin{array}{c}0.286^{* * * *} \\
(0.062)\end{array}$ \\
\hline $\ln$ (Total Beds) & $\begin{array}{c}0.107^{* * *} \\
(0.020)\end{array}$ & $\begin{array}{c}0.108^{* * * *} \\
(0.021)\end{array}$ & $\begin{array}{c}0.107 * * * \\
(0.020)\end{array}$ & $\begin{array}{c}0.107 * * * \\
(0.020)\end{array}$ & $\begin{array}{c}0.107 * * * \\
(0.020)\end{array}$ & $\begin{array}{c}0.107^{* * * *} \\
(0.020)\end{array}$ & $\begin{array}{c}0.107 * * * \\
(0.020)\end{array}$ & $\begin{array}{c}0.108 * * * \\
(0.020)\end{array}$ & $\begin{array}{c}0.108 * * * \\
(0.020)\end{array}$ & $\begin{array}{c}0.107 * * * \\
(0.020)\end{array}$ & $\begin{array}{c}0.107 * * * \\
(0.020)\end{array}$ \\
\hline$\%$ Medicaid & $\begin{array}{l}0.070 \\
(0.052)\end{array}$ & $\begin{array}{c}0.073 \\
(0.053)\end{array}$ & $\begin{array}{l}0.070 \\
(0.052)\end{array}$ & $\begin{array}{l}0.070 \\
(0.052)\end{array}$ & $\begin{array}{c}0.071 \\
(0.052)\end{array}$ & $\begin{array}{c}0.070 \\
(0.052)\end{array}$ & $\begin{array}{l}0.070 \\
(0.052)\end{array}$ & $\begin{array}{c}0.070 \\
(0.052)\end{array}$ & $\begin{array}{l}0.070 \\
(0.052)\end{array}$ & $\begin{array}{c}0.069 \\
(0.052)\end{array}$ & $\begin{array}{c}0.069 \\
(0.052)\end{array}$ \\
\hline For-Profit & $\begin{array}{c}0.054^{* * *} \\
(0.020)\end{array}$ & $\begin{array}{c}0.054 * * * \\
(0.020)\end{array}$ & $\begin{array}{c}0.054 * * * \\
(0.020)\end{array}$ & $\begin{array}{c}0.054 * * * \\
(0.020)\end{array}$ & $\begin{array}{c}0.054 * * * \\
(0.020)\end{array}$ & $\begin{array}{c}0.054 * * * \\
(0.020)\end{array}$ & $\begin{array}{c}0.054 * * * \\
(0.020)\end{array}$ & $\begin{array}{c}0.054^{* * *} \\
(0.020)\end{array}$ & $\begin{array}{c}0.054 * * * \\
(0.020)\end{array}$ & $\begin{array}{c}0.054 * * * \\
(0.020)\end{array}$ & $\begin{array}{c}0.054 * * * \\
(0.020)\end{array}$ \\
\hline Observations & 33,896 & 33,388 & 33,884 & 33,864 & 33,766 & 33,884 & 33,849 & 33,829 & 33,888 & 33,883 & 33,882 \\
\hline Number of hospitals & 2,836 & 2,741 & 2,834 & 2,831 & 2,817 & 2,834 & 2,830 & 2,826 & 2,835 & 2,834 & 2,834 \\
\hline R-squared (within) & 0.570 & 0.572 & 0.570 & 0.570 & 0.571 & 0.570 & 0.570 & 0.571 & 0.570 & 0.570 & 0.570 \\
\hline $\begin{array}{l}\mathrm{p} \text {-value for } \mathrm{H}_{0} \text { : coefficients for } \\
\text { Adj* }(\mathrm{t}>0) \text { and Non-Adj* }(\mathrm{t}>0) \\
\text { are same }\end{array}$ & 0.179 & 0.403 & 0.185 & 0.187 & 0.234 & 0.188 & 0.132 & 0.197 & 0.150 & 0.197 & 0.205 \\
\hline
\end{tabular}


Appendix Table 4:

Robustness Checks

\begin{tabular}{|c|c|c|c|c|c|c|}
\hline & \multicolumn{3}{|c|}{ FTC (Control Group 2) } & \multicolumn{3}{|c|}{ Broad Sample (Control Group 2) } \\
\hline & (1) & $(2)$ & (3) & (4) & $(5)$ & (6) \\
\hline & In Text & $\begin{array}{c}\text { Drop controls } \\
\text { (except year } \\
\text { effects) }\end{array}$ & $\begin{array}{c}\text { For-Profit year } \\
\text { effects }\end{array}$ & In Text & $\begin{array}{c}\text { Drop controls } \\
\text { (except year } \\
\text { effects) }\end{array}$ & $\begin{array}{c}\text { For-Profit year } \\
\text { effects }\end{array}$ \\
\hline \multirow[t]{2}{*}{ Adj Treated $*(t=0)$} & 0.010 & 0.023 & 0.011 & 0.035 & 0.033 & 0.034 \\
\hline & $(0.016)$ & $(0.017)$ & $(0.017)$ & $(0.029)$ & $(0.030)$ & $(0.029)$ \\
\hline \multirow[t]{2}{*}{ Adj Treated* $(t>0)$} & $0.064 * * *$ & $0.076 * * *$ & $0.079 * * *$ & $0.093 * *$ & $0.093 * *$ & $0.088 * *$ \\
\hline & $(0.023)$ & $(0.023)$ & $(0.024)$ & $(0.046)$ & $(0.047)$ & $(0.044)$ \\
\hline \multirow[t]{2}{*}{ Non-Adj Treated $*(t=0)$} & -0.048 & -0.043 & -0.032 & -0.019 & -0.013 & -0.020 \\
\hline & $(0.058)$ & $(0.058)$ & $(0.059)$ & $(0.027)$ & $(0.026)$ & $(0.026)$ \\
\hline \multirow[t]{2}{*}{ Non-Adj Treated $*(t>0)$} & -0.013 & -0.014 & 0.030 & -0.032 & -0.036 & -0.041 \\
\hline & $(0.054)$ & $(0.056)$ & $(0.056)$ & $(0.034)$ & $(0.032)$ & $(0.031)$ \\
\hline \multirow[t]{2}{*}{$\ln (\mathrm{CMI})$} & $0.286^{* * *}$ & & $0.285 * * *$ & 0.213 & & 0.208 \\
\hline & $(0.062)$ & & $(0.062)$ & $(0.160)$ & & $(0.162)$ \\
\hline \multirow[t]{2}{*}{$\ln ($ Total Beds $)$} & $0.107 * * *$ & & $0.111 * * *$ & $0.117 *$ & & $0.116^{*}$ \\
\hline & $(0.020)$ & & $(0.020)$ & $(0.067)$ & & $(0.067)$ \\
\hline \multirow[t]{2}{*}{$\%$ Medicaid } & 0.070 & & 0.067 & 0.164 & & 0.170 \\
\hline & $(0.052)$ & & $(0.052)$ & $(0.149)$ & & $(0.148)$ \\
\hline \multirow[t]{2}{*}{ For-Profit } & $0.054 * * *$ & & & 0.072 & & \\
\hline & $(0.020)$ & & & $(0.049)$ & & \\
\hline Observations & 33,896 & 34,515 & 33,896 & 4,422 & 4,503 & 4,422 \\
\hline Number of hospitals & 2,836 & 2,862 & 2,836 & 711 & 729 & 711 \\
\hline R-squared (within) & 0.570 & 0.564 & 0.573 & 0.435 & 0.428 & 0.440 \\
\hline $\mathrm{p}$-value for $\mathrm{H}_{0}$ : coefficients for & & & & & & \\
\hline $\begin{array}{l}\operatorname{Adj} *(t>0) \text { and Non-Adj*(t>0) } \\
\text { are same }\end{array}$ & 0.186 & 0.135 & 0.408 & 0.021 & 0.018 & 0.014 \\
\hline
\end{tabular}

Notes: Standard errors clustered by hospital, *** $\mathrm{p}<0.01, * * \mathrm{p}<0.05, * \mathrm{p}<0.1$ 
Appendix Table 5:

Broad Sample, Effects by Minimum Distance between Merging, Adjacent Hospitals

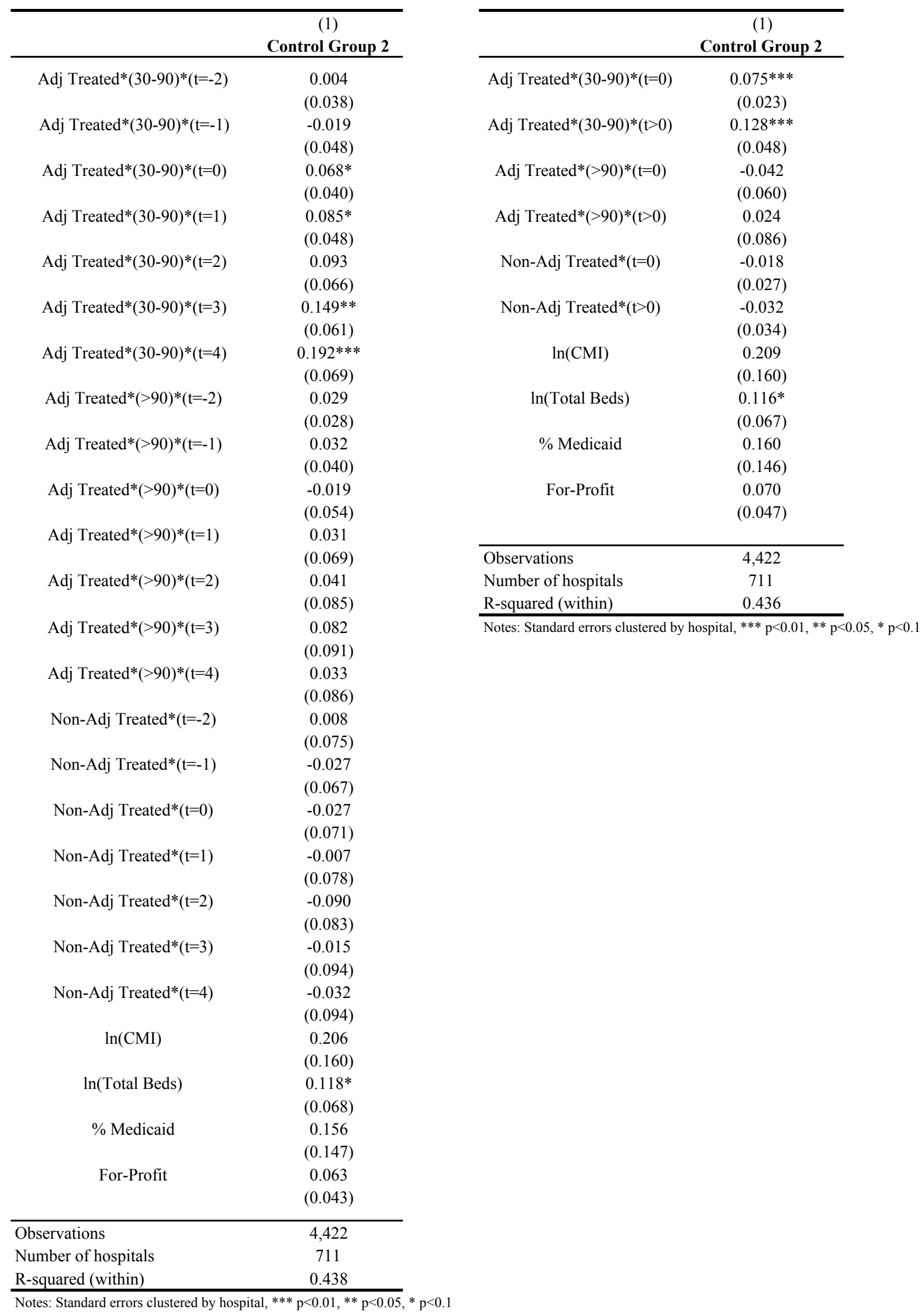

